\title{
LA INDUSTRIA ÓSEA MAGDALENIENSE DE CUEVA OSCURA DE ANIA (LAS REGUERAS, ASTURIAS). ESTUDIO TECNOMORFOLÓGICO Y CRONOESTRATIGRAFÍA (*)
}

\author{
THE MAGDALENIAN BONE INDUSTRY OF CUEVA OSCURA DE ANIA (LAS REGUERAS, \\ ASTURIAS). A TECHNOMORPHOLOGICAL AND CHRONOSTRATIGRAPHIC STUDY
}

\author{
GEMA ELVIRA ADÁN ÁLVAREZ (**) \\ EDUARDO GARCÍA SÁNCHEZ (***) \\ JOSÉ MANUEL QUESADA LÓPEZ (****)
}

\begin{abstract}
RESUMEN
Cueva Oscura de Ania (Las Regueras, Asturias) cuenta con un yacimiento que abarca Magdaleniense y Aziliense. Excavado entre 1975 y 1980, el registro arqueológico de la Cueva ha permanecido prácticamente inédito hasta la fecha. El presente trabajo ofrece resultados del estudio tecnomorfológico del conjunto óseo magdaleniense, uno de los más numerosos para este tecnocomplejo en la Cornisa Cantábrica, con 309 piezas. El espectro tipológico y técnico muestra que representa dos horizontes industriales: Magdaleniense medio evolucionado y la transición Magdaleniense medio/Superior o Magdaleniense superior inicial. Desde un punto de vista cronoestratigráfico, se sitúa entre Bölling/ Cantábrico VI y Dryas II/Cantábrico VII.
\end{abstract}

\footnotetext{
ABSTRACT

Cueva Oscura de Ania (Las Regueras, Asturias) is a site with Magdalenian and Azilian levels. Excavated between

(*) El presente trabajo presenta parte de los resultados del proyecto Análisis de los materiales depositados en el "Museo Arqueológico de Asturias" de Cueva Oscura de Ania (Las Regueras), estudio desarrollado en el marco de la Convocatoria 2000 del Programa de Subvenciones para Proyectos de Investigación Arqueológica del Principado de Asturias (Boletín Oficial del Principado de Asturias, 4/VIII/2000 y Corrección del 28/IX/2000).

(**) Doctora en Prehistoria por la Universidad de Salamanca. Correo electrónico: geadan@telepolis.com

$(* * *)$ Becario Predoctoral UNED. Dpto. de Prehistoria e Historia Antigua. Universidad Nacional de Educación a Distancia. C/ Senda del Rey, 7. 28040 Madrid. Correo electrónico: homoergaster@bec.uned.es

(****) Becario Postdoctoral Comunidad de Madrid. Dpto. de Prehistoria e Historia Antigua. Universidad Nacional de Educación a Distancia. C/ Senda del Rey, 7. 28040 Madrid. Correo electrónico: jmquesada@inicia.es

Recibido: 18-XII-01; aceptado: 8-IV-02.
}

1975 and 1980, most of its archaeological record has remained practically unpublished. The present paper presents the results of the study of Magdalenian bone and antler assemblage, one of the largest known for Cantabrian Magdalenian, with 309 items. The typological and technical analysis of this assemblage shows that there are at least two archaeological phases: Developed Middle Magdalenian and Middle Magdalenian/Upper Magdalenian transition or Lower Upper Magdalenian. These archaeological remains have a chronology between Bölling/Cantábrico VII and Dryas II/Cantábrico VI paleoclimatological phases.

Palabras clave: Cueva Oscura de Ania. Magdaleniense medio evolucionado. Magdaleniense superior inicial. Industria ósea. Paleolítico superior final. Bölling/Cantábrico VI. Dryas II/Cantábrico VII. Cuenca del Nalón. Asturias. Cornisa Cantábrica.

Key words: Cueva Oscura de Ania. Upper Middle Magdalenian. Lower Upper Magdalenian. Bone and antler assemblage. Upper Paleolithic; Bölling/Cantábrico VI. Dryas II/ Cantábrico VII. Nalón basin. Asturias. Cantabrian region.

\section{PREÁMBULO}

El registro arqueológico procedente de la cuenca del Nalón ocupa un lugar destacado en el conocimiento de los tecnocomplejos magdalenienses de la Cornisa Cantábrica (Figs. 1 y 2). La clásica secuencia de la Cueva de La Paloma (Soto de Las Regueras) y los profusos avances de la documentación exhumada en la Cueva de Las Caldas (San Juan de Priorio, Oviedo) han sido los puntales bá- 


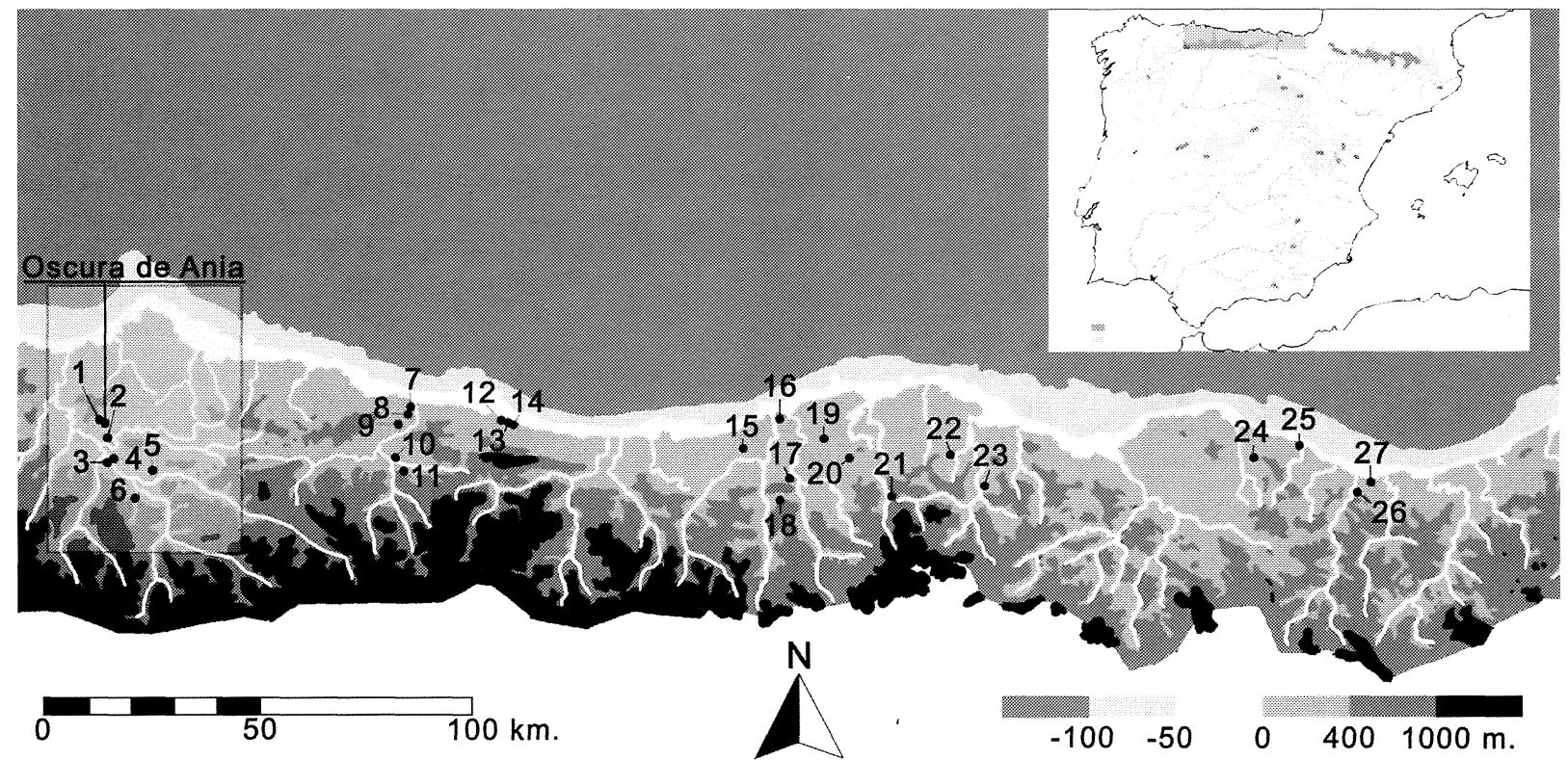

Fig. 1. Localización de algunos de los yacimientos cantábricos citados en el texto (modificado a partir de González Sainz 1989a: 16, Fig. 2). El área destacada corresponde a la representada con mayor detalle en la Figura 2. 1. La Paloma; 2. Sofoxó; 3. La Lluera I; 4. Las Caldas; 5. La Viña; 6. Entrefoces; 7. Tito Bustillo; 8. La Cuevona de Ribadesella; 9. La Lloseta; 10. Los Azules I; 11. La Güelga; 12. Cueto de la Mina; 13. La Riera; 14. Balmori; 15. Altamira; 16. La Pila; 17. El Castillo; 18. Hornos de la Peña; 19. El Pendo; 20. Morín; 21. El Rascaño; 22. La Chora; 23. El Valle; 24. Santimamiñe; 25. Lumentxa; 26. Ermittia; 27. Urtiaga.

sicos para el estudio de estos contextos en la comarca. A ello cabe unir las informaciones disponibles sobre los abrigos de Entrefoces (La Foz de Morcín) y de La Viña (La Manzaneda, Oviedo). Este panorama se completa con los indicios, problemáticos y ambiguos en ocasiones, de ocupaciones que podrían ubicarse en diferentes fases del magdaleniense en las cuevas de Requexu (Ferreros, Ribera de Arriba); El Ángel (Tuñón, Santo Adriano); La Lluera I (San Juan de Priorio, Oviedo); Los Murciélagos (Portazgo, Oviedo); La Ancenia (Balsera, Las Regueras); Mestas III (Taoces, Las Regueras); Sofoxó (Rañeces, Las Regueras); La Peña de Candamo (San Román, Candamo) y la desaparecida Oscura de Perán (Perlora, Carreño).

A este listado de yacimientos debe sumarse el depósito Magdaleniense de Cueva Oscura de Ania (Las Regueras, Asturias), una cavidad de dimensiones modestas situada en la zona media de la cuenca del Nalón -en las proximidades de las cuevas de La Paloma; Sofoxó I y Mestas III - llamada a convertirse en punto de referencia para el conocimiento del Magdaleniense y el Aziliense en la comarca (Adán et al. 1999: 229; 2001).

El yacimiento se excavó en el marco del proyec- to de investigación en la cuenca del Nalón planteado a mediados de la década de 1970 por Gómez Tabanera (1975), por aquel entonces al frente del Seminario de Prehistoria de la Universidad de Oviedo. Los trabajos de campo, codirigidos por el propio Gómez Tabanera y Pérez Pérez entre 1975 y 1980 (1992: 625), documentaron un depósito arqueológico de potencia considerable (1) en el que se diferenciaron varios niveles de filiación aziliense y magdaleniense (Fig. 3). Sin embargo, el registro de la cueva, depositado en el Museo Arqueológico de Asturias (Oviedo; MAA desde ahora en adelante), ha permanecido prácticamente inédito. Desde 1999 venimos revisando estos materiales y el presente trabajo expone parte de los resultados obtenidos hasta la fecha.

(1) Durante una visita al yacimiento pudimos comprobar que el sector meridional de la excavación, aquel a donde se refieren las siglas de los materiales que hemos estudiado, superaba los 180 $\mathrm{cm}$ de potencia en algunas zonas. El reconocimiento en cuestión estuvo motivado por la toma de muestras en el perfil estratigráfico por parte del Dr. Brooks Elwood (Departamento de Geología y Geofísica; Louisiana State University). Las mismas se tomaron con vistas a obtener una curva climática de la secuencia por medio de cálculo de susceptibilidad magnética y cicloestratigrafía. Los resultados del análisis aún no estaban listos en el momento de redactarse este trabajo. 


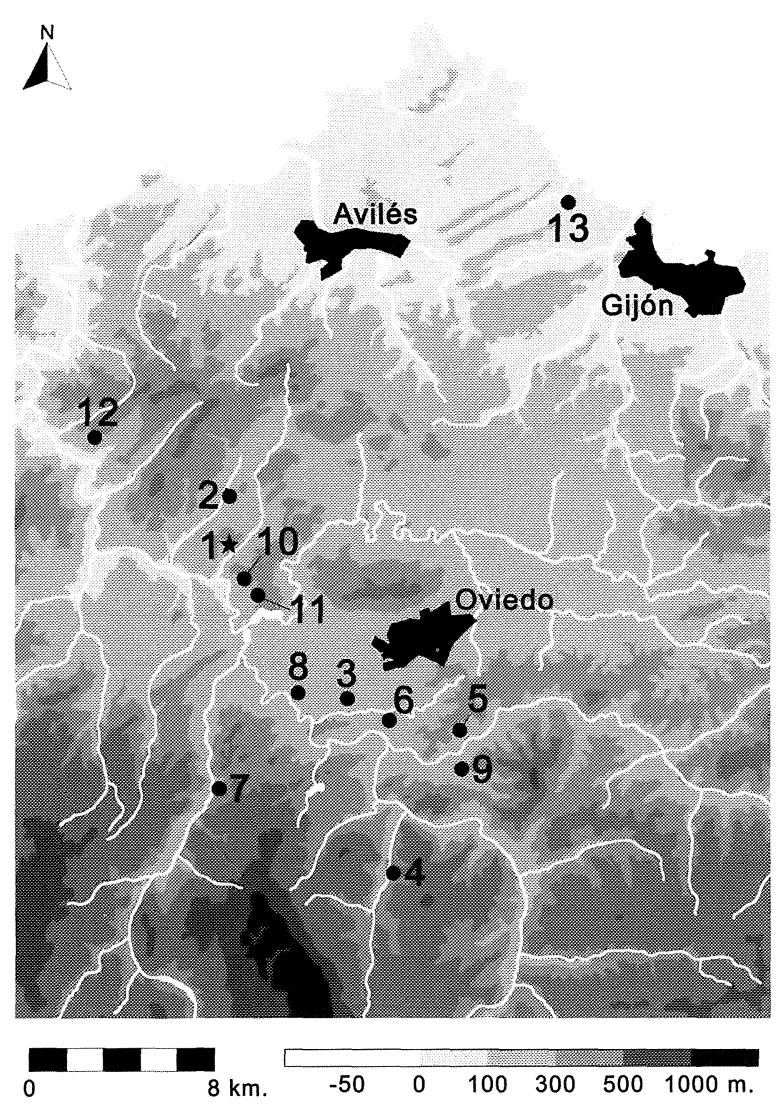

Fig. 2. Localización de los yacimientos de la cuenca del Nalón mencionados en el texto. 1 Oscura de Ania; 2. La Paloma; 3. Las Caldas; 4. Entrefoces; 5. La Viña; 6. Requexu; 7. El Ángel; 8. La Lluera I; 9. Los Murciélagos; 10. Mestas III, también conocida como Cueva del Gitano; 11. Sofoxó; 12. La Peña de Candamo; 13. Oscura de Perán.

\section{EL MAGDALENIENSE DE CUEVA OSCURA DE ANIA: CONSIDERACIONES PRELIMINARES}

En el transcurso de los trabajos de excavación (2) aparecieron dos trabajos que presentaban la estratigrafía y alguna pieza significativa (Gómez Tabanera et al. 1975; Pérez Pérez 1977). Sin embargo, poco más se publicó sobre el registro (3). Las estra-

(2) La excavación interesó 6 metros cuadrados en el sector meridional del vestíbulo (Fig. 4). En el sector septentrional, separado del anterior por grandes bloques de caliza caídos por colapso gravitacional, se realizó una limpieza de revuelto. Éste era obra tanto de un furtivo como del uso de la Cueva como escondrijo de armas y objetos de valor durante la Guerra Civil española (Gómez Tabanera et al. 1975: 61).

(3) En concreto, dos artículos sobre objetos singulares del mismo (Pérez Pérez 1982; 1992) y someras referencias aisladas a algunos elementos de industria ósea (Gómez Tabanera 1980: 69, $117,178)$.

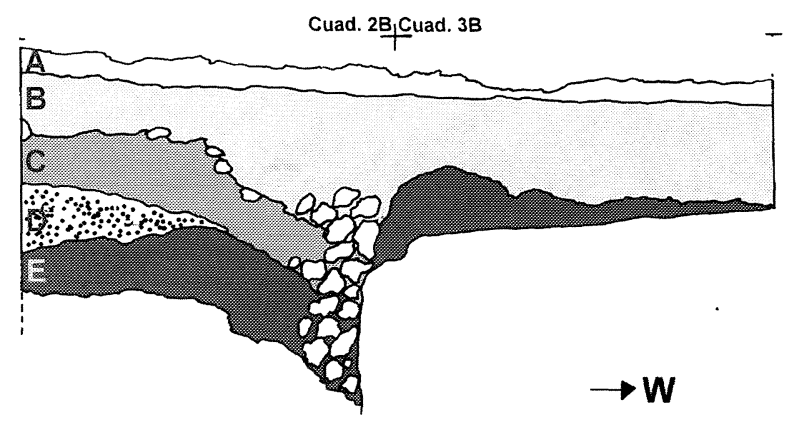

Fig. 3. Perfil estratigráfico (norte) del área de excavación sur de Cueva Oscura de Ania (modificado a partir de Gómez Tabanera et alii 1975: 62, fig. 2). Se hace necesario señalar que una visita al yacimiento nos ha prevenido sobre la correspondencia real del dibujo publicado con la secuencia. La impresión que se desprende es que éste simplifica excesivamente la secuencia, especialmente su tramo inferior. A tenor de las fechas de publicación y las apreciadas en el etiquetado de los 'materiales, es muy posible que esta estratigrafía se dibujara cuando el sondeo aún no había alcanzado su base en toda la superficie del área de excavación. En ausencia de datos de primera mano que aclaren la situación, la correspondencia con los niveles definidos en las noticias del yacimiento publicadas hasta la fecha plantea serias dudas y nuestra propuesta debe entenderse como una reconstrucción hipotética a contrastar. ¿A=Nivel superficial; $\mathrm{B}=$ Nivel $1 /$ Horizontes 0 y $0 \mathrm{a} ; \mathrm{C}=$ Nivel $2 /$ Horizontes $0 \mathrm{~b}$ y $0 \mathrm{c} ; \mathrm{D}=$ Nivel de arcillas blancas; $\mathrm{E}=$ Estrato $3 /$ Niveles $3,3 \mathrm{a}$ y $3 b$ ?

tigrafías publicadas (Gómez Tabanera et al. 1975: 62, fig. 2; Pérez Pérez 1977: 182-183, figs. 1b y 1c) no ofrecen leyendas que identifiquen los diferentes niveles descritos y consignados en el etiquetado de los materiales (Fig. 3) (4). El depósito magdale-

(4) Una visita al yacimiento nos induce a pensar que los dibujos publicados han simplificado en exceso la secuencia, en especial su tramo inferior. En las representaciones no se aprecia que los excavadores establecieron una subdivisión en tres subniveles: Nivel 3, Nivel 3a y Nivel 3b. Más aún, sospechamos que las representaciones de la estratigrafía del yacimiento se realizaron y publicaron antes de la exhumación del registro que aquí presentamos: la fecha de los trabajos en que se difundieron estas estratigrafías (Gómez Tabanera et al. 1975; Pérez Pérez 1977) es anterior a la consignada en los materiales magdalenienses de Oscura de Ania por nosotros estudiados. Aunque el trabajo de Manuel Pérez figura con fecha de 1977, se trata de una comunicación presentada al XIV Congreso Nacional de Arqueología, celebrado en Vitoria entre los días 7 y 11 de octubre de 1975, año en el que se iniciaron las excavaciones en el yacimiento. El texto mismo denota que su redacción data de fechas inmediatamente anteriores o posteriores al desarrollo del Congreso: "(...) en los últimos años, se han descubierto un buen número de estaciones de distintas épocas, entre las cuales sólo algunas se mencionan en publicaciones aisladas, mientras que otras permanecen totalmente inéditas. A este último grupo correspondió, hasta el pasado verano, Cueva Oscura de Ania (...)" (Pérez Pérez 1977: 180; el subrayado es nuestro). La nomenclatura de las etiquetas señala que la excava- 


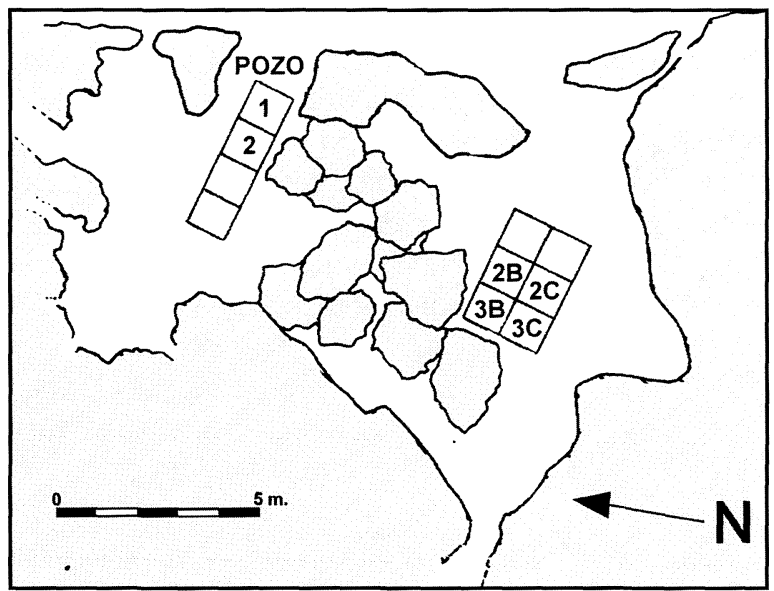

Fig. 4. Plano del vestíbulo de Cueva Oscura de Ania con la ubicación de las cuadrículas de excavación (modificado a partir de Gómez Tabanera et al. 1975: 62, fig. 1).

niense, denominado genéricamente como "Nivel 3", fue definido en primera instancia como "Magdaleniense Superior Cantábrico" (Gómez Tabanera et al. 1975: 65; Pérez Pérez 1977: 191), especificando que el hallazgo descontextualizado de dos pequeños fragmentos de varillas semicilíndricas con decoración curvilínea en relieve "tipo Isturitz" pudiera corresponder bien a una dispersión más tardía de este tipo desde el foco pirenaico, bien a una ocupación anterior de la Cueva (Pérez Pérez 1982: 84). Sobre este Nivel 3 descansan un nivel de arcillas estériles y los niveles 1 y 2 . La revisión del registro ha permitido definir estos últimos como Aziliense clásico temprano y Aziliense antiguo, respectivamente (Adán et al. 1999; 2001; e. p. a).

La sedimentología del yacimiento se encontraba en estudio en el momento en que vieron la luz los primeros trabajos sobre el mismo (Pérez Pérez 1977: 184) y los comentarios publicados sobre las características del Nivel 3 son muy someros. Se limitan a ubicarlo a finales de Dryas I y a definirlo como un depósito variable con una matriz de tierras amarillentas que envolvía numerosos "restos termoclásticos" y se transformaba progresivamente en tierras más obscuras y sueltas, con una granulometría más fina y menor presencia de crioclastos (Pérez Pérez 1992: 641-642, nota 15). Bien es cierto

ción del Nivel 3 comenzó en la campaña de 1977, en el cuadro 2b. En 1978 se sondearon los cuadros 1b; 1c; 2b; y 2c con Nivel 3 y el 1c con una nueva capa, Nivel 3a. En 1979 todos los cuadros pertenecen al Nivel 3a ( $1 \mathrm{~b}$; $1 \mathrm{c}$ y $2 \mathrm{~b})$ y en 1980 se prosiguió con el mismo y se detectaba un nuevo estrato, el Nivel 3b. Sospechamos que quedó casi sin configurar ante la premura del cierre, no ya de la campaña sino de la misma excavación en el yacimiento.

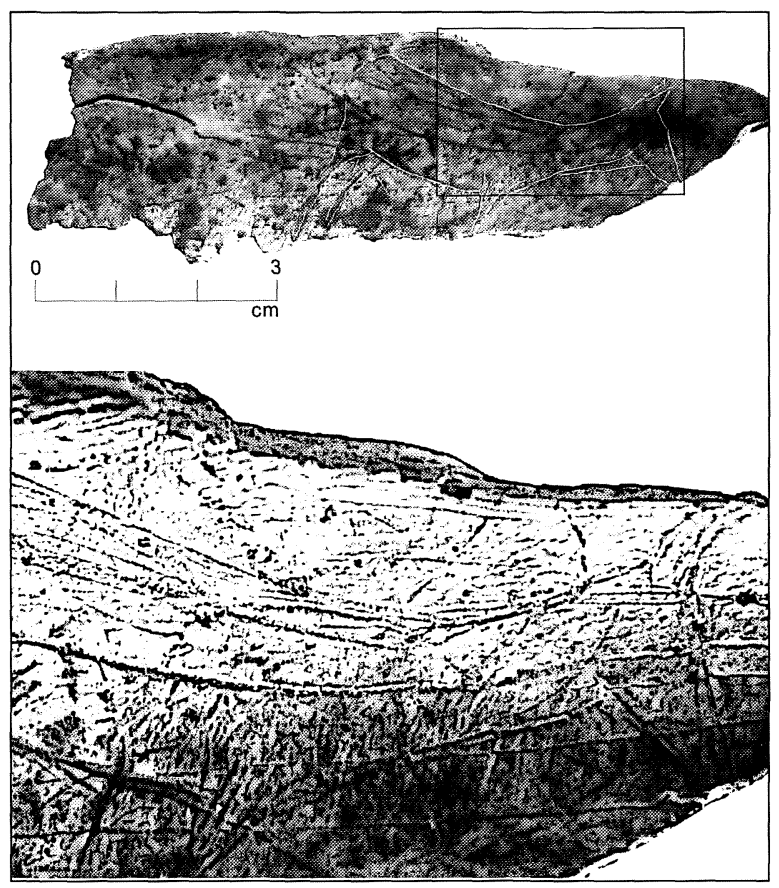

Fig. 5. Fragmento de escápula de ciervo con grabados del Nivel 3a.

que de forma tangencial se menciona la diferenciación de dos capas magdalenienses dentro del Nivel 3 (3a y 3b), sin mayores precisiones (ibidem: 642). En realidad, el etiquetado de los materiales indica claramente que durante el proceso de excavación se identificaron tres subniveles dentro del Nivel 3: Nivel 3; Nivel 3a y Nivel 3b.

La caracterización de su industria lítica apenas señala el predominio de buriles sobre raspadores, con una proporción notable de diedros; un porcentaje "proporcionalmente alto" de utillaje microlaminar, con presencia notable de microgravettes y la abundancia de "raspadores nucleiformes", seguidos en número por atípicos (Pérez Pérez 1992: $640)$. En cuanto a la industria ósea, en primera instancia se comentó la existencia, entre "escasas muestras de azagayas, agujas y punzones", de un arpón de sección subtriangular con acanaladuras en dorso e incisiones en dientes y de dos tubos óseos con decoración lineal en paralelo (Pérez Pérez 1977: 191, 194-195: figs. 10.4, 10.2, 10.5). En un trabajo posterior (Pérez Pérez 1992: 641), dedicado al análisis de una excepcional pieza de arte mueble (Fig. 5), se destacó la presencia en el Nivel 3 a de un segundo arpón y de un número indeterminado de varillas semicilíndricas con relieve tuberculado. 
Una pieza ósea singular del Magdaleniense de Oscura de Ania, conocida únicamente por fotografía y un lacónico comentario a pie de ilustración (Gómez Tabanera 1980: 69), es un arpón grabado con la figura de un bóvido y diversos signos, particularmente interesante porque las representaciones realistas sobre los denominados objetos de uso precario son raras (5) (Menéndez Fernández 1997: 141). Pero no hemos podido estudiar este objeto, pues no se encuentra depositada en el MAA (6).

$\mathrm{Si}$ bien las primeras noticias sobre el yacimiento afirmaban una gran similitud entre los conjuntos lítico y óseo de ambas capas magdalenienses (Pérez Pérez 1992: 642), un primer trabajo de revisión destacó la ausencia de arpones en el Nivel 3b y la presencia de numerosas varillas plano convexas decoradas en el Nivel 3a (Adán Álvarez 1997: 85). Las descripciones de los arpones y la somera caracterización de la industria lítica llevaron a incluir la cueva en la nómina de yacimientos cantábricos donde se encuentran representadas las primeras manifestaciones del Magdaleniense superior (González Sainz 1989a: 31). No obstante, la ubicación cronoestratigráfica precisa del depósito se mantuvo pendiente de resolución.

\section{EL MAGDALENIENSE DE CUEVA OSCURA DE ANIA: ESTUDIO TECNOTIPOLÓGICO DE LA INDUSTRIA ÓSEA (7)}

Las descripciones y consideraciones expuestas en los párrafos anteriores no dan idea cabal ni de la

(5) De confirmarse que este arpón realmente cuenta con la decoración descrita, uno de sus paralelos (en cuanto a combinación de soporte y figura naturalista) más cercano geográficamente sería una azagaya con grabado de cierva perteneciente al Magdaleniense final de La Paloma (Corchón 1986: 400, 403, fig. 144.1). Dejando a un lado dos serpentiformes de sendos arpones de La Pila (Cuchía, Miengo; Cantabria), motivos que se adaptan mejor al campo decorativo que ofrecen los arpones (Menéndez Fernández 1997: 141), se conoce el ejemplo de un oso o lobo sobre un arpón de El Castillo (Puente Viesgo); un caballo en otro de El Pendo (El Escobedo de Camargo) y una cabra en un ejemplar de El Rascaño (Mirones de Miera), en Cantabria (Moure 1985: 117).

(6) Además de este objeto, hemos notado la ausencia en el MAA de otros representados en las publicaciones sobre el yacimiento: una azagaya con decoración lineal, el comentado arpón con una fila de siete dientes ganchudos; dos tubos óseos con decoración lineal (Pérez Pérez, 1977: 195, figs. 10.1, 10.4, 10.5 y 10.6) y los dos fragmentos de varillas clasificadas como "tipo Isturitz" halladas en el revuelto del sector septentrional (Pérez Pérez, 1982: 81-83, figs. 2 y 3).

(7) Un avance a este estudio, en la práctica un mero recuento tipológico, fue presentado como comunicación al XXVI Congre- complejidad estratigráfica ni del volumen y calidad del conjunto arqueológico de este "Nivel 3". Ya hemos señalado que la revisión de los materiales correspondientes a este último ha permitido constatar que durante la excavación se diferenciaron tres niveles magdalenienses, denominados de techo a base por sus excavadores Nivel 3; Nivel 3a y Nivel $3 b$. Para evitar confusiones y respetar la nomenclatura de etiquetado, a partir de este momento designaremos el depósito magdaleniense de la Cueva como "Estrato III", dejando la denominación " $\mathrm{Ni}_{-}$ vel 3" o "N.3" para la unidad superior del mismo. La industria ósea perteneciente al Estrato III depositada en el MAA comprende un total de 309 ejemplares entre piezas en proceso de elaboración, morfotipos y arte sobre soportes no elaborados (8) (Gráficos 12 ; tabla 1). Nos encontramos, pues, ante uno de los conjuntos más nutridos de aquellos conocidos para el Magdalenieńse medio o superior cantábrico (9).

so Nacional de Arqueología, celebrado en Zaragoza entre los días 18 y 21 de abril de 2001 (Adán et al. e. p. b). El estudio de las técnicas empleadas en la manufactura de los diferentes conjuntos óseos de Cueva Oscura se ha visto dificultado por el enmascaramiento y/o la desaparición en numerosas piezas de marcas antrópicas, fueran estas de trabajo o uso. Esta circunstancia estuvo motivada por los tratamientos de limpieza y consolidación a que fueron sometidos los efectivos de la colección antes de su entrega al MAA. A la hora de abordar el análisis tecnomorfológico del conjunto óseo hemos utilizado la metodología y la tipología desarrollada por una de nosotros en la realización de su tesis doctoral: Adán Álvarez, G. E. (1995): Industria ósea del Tardiglaciar en Asturias: Análisis arqueozoológico y estudio de los métodos de trabajo sobre el utillaje óseo. Tesis doctoral inédita. Universidad de Salamanca, Salamanca. Una exposición pormenorizada de los objetivos y la sistemática de este método, incluyendo los criterios seguidos para discriminar los diferentes formas de trabajo óseo identificadas en el registro, puede encontrarse en los dos primeros capítulos de la monografía que resume aquel trabajo de investigación (Adán Álvarez 1997: 15-47).

(8) En el recuento del conjunto no hemos incluido aquellos materiales ausentes de los fondos del MAA y publicados por los excavadores del yacimiento, limitándonos a utilizar para nuestro estudio tecnomorfológico aquellos elementos que hemos podido analizar de primera mano. Entre la industria ósea tampoco hemos incluido 54 restos con marcas de carnicería que, a tenor de su etiquetado, fueron interpretados como piezas decoradas por los excavadores del yacimiento. Hemos de aclarar que no toda la fauna con marcas de carnicería del depósito se encuentra representada en la colección. En realidad, los restos de fauna que figuran entre el material de Cueva Oscura de Ania depositado en el MAA no constituyen la totalidad de los exhumados en el yacimiento. Tenemos constancia de que la mayor parte de la fauna diagnóstica, cuyo estudio se encargó al Dr. F. J. Villalta (Gómez Tabanera et al., 1975), se encuentra repartida entre el Museo Nacional de Ciencias Naturales de Madrid y una institución catalana. Aquellos almacenados en el Museo asturiano han sido cuantificados por el paleontólogo Diego J. Álvarez Láo [Adán Álvarez, G. E.; García Sánchez, E. y Quesada López, J. M. (2000): Informe del análisis de los materiales depositados en el "Museo Arqueológico de Asturias" de la Cueva Oscura de Ania (Las Regueras); Consejería de Educación y Cultura del Principado de Asturias, Oviedo. Inédito].

(9) Esta abundancia de materiales podría estar relacionada con una ocupación del yacimiento cuando menos tan intensa 


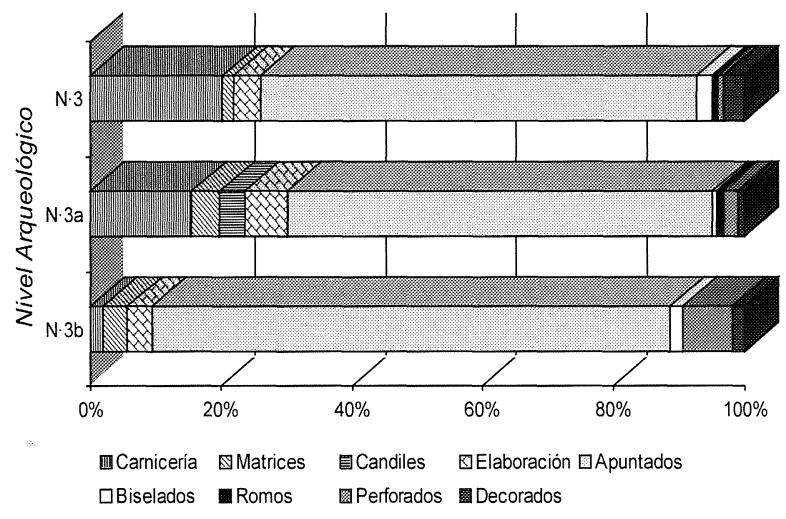

Gráf. 1. Distribución porcentual en categorías del conjunto óseo magdaleniense de Cueva Oscura de Ania.

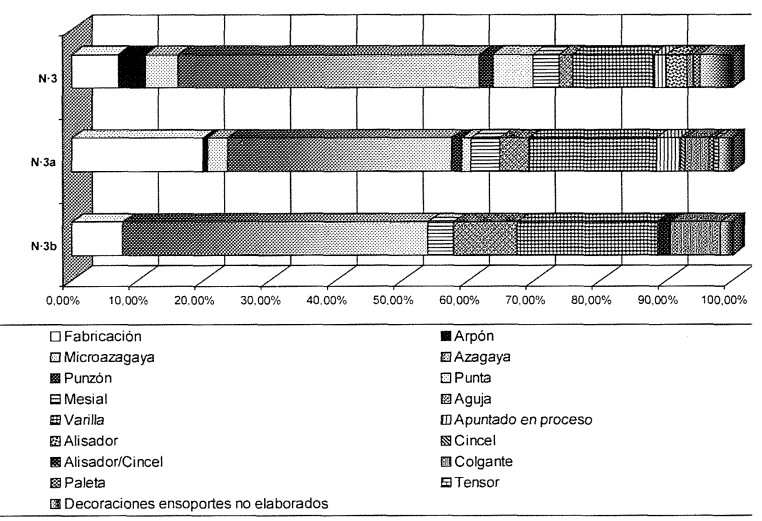

Gráf. 2. Distribución por morfotipos y niveles del conjunto óseo magdaleniense de Cueva Oscura de Ania.

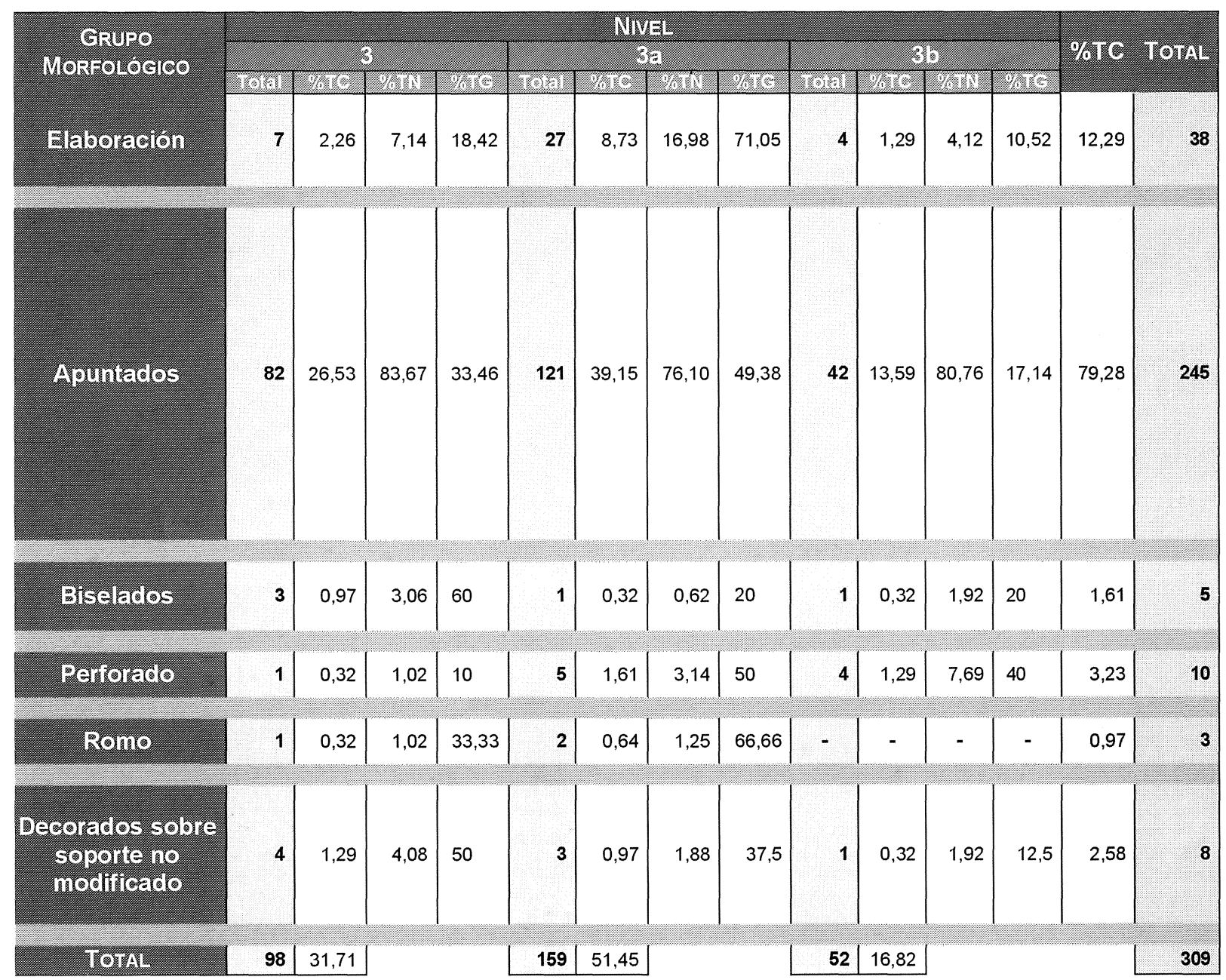

Tab. 1. Listado sintético del conjunto óseo magdaleniense de Cueva Oscura de Ania según grupos morfológicos y morfotipos. Clave: \% TC: porcentaje sobre el total del conjunto óseo restos; \% TN: porcentaje sobre el total del conjunto óseo del nivel correspondiente; \%GN: porcentaje sobre el total del grupo morfológico dentro del nivel correspondiente; S/P: sin proximal; MB: monobiselada; DB: Bisel doble; BR: base roma; BP: bisel aplastado; N/T: no tuberculada; T: tuberculada. 


\begin{tabular}{|c|c|c|c|c|c|c|c|c|c|c|c|c|c|c|c|}
\hline \multirow[t]{3}{*}{ 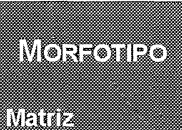 } & \multicolumn{12}{|c|}{ Novel. } & IIOTIL & \multicolumn{2}{|c|}{9010} \\
\hline & 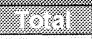 & 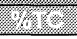 & 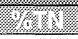 & (2.64) & 4reviln & 1.48 & 1.64 & 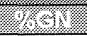 & 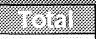 & 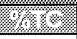 & 4.40 & $1.8 \mathrm{ser}^{4}$ & & & \\
\hline & 2 & 0,64 & 2,04 & 28,57 & 8 & 2,58 & 5,03 & 29,62 & 1 & 0,32 & 1,92 & 25 & 11 & & 3,57 \\
\hline Conolitetion & - & - & - & - & 7 & 2,26 & 4,40 & 25,92 & 1 & 0,32 & 1,92 & 25 & 8 & & 2,59 \\
\hline vaula: & - & - & - & - & 12 & 3,88 & 7,54 & 44,44 & 2 & 0,64 & 3,84 & 50 & 14 & & 4,54 \\
\hline 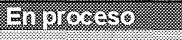 & 5 & 1,61 & 5,10 & 71,42 & - & - & - & - & - & - & - & - & 5 & & 1,62 \\
\hline Apoon & 4 & 1,29 & 4,08 & 4,87 & 1 & 0,32 & 0,62 & 0,82 & - & - & - & - & 5 & & 1,62 \\
\hline Vilerearabays: & 5 & 1,61 & 5,10 & 6,09 & 4 & 1,29 & 2,51 & 3,30 & - & - & - & - & 9 & & 2,92 \\
\hline 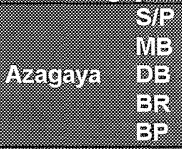 & $\begin{array}{rr}33 & \\
5 & \\
5 & 45 \\
2 & \\
- & \\
\end{array}$ & 14,56 & 45,91 & 54,87 & $\begin{array}{rr}46 & \\
2 & \\
18 & 69 \\
2 & \\
1 & \\
\end{array}$ & 22,33 & 28,93 & 38,01 & $\begin{array}{r}10 \\
1 \\
1324 \\
- \\
- \\
\end{array}$ & 7,76 & 46,15 & 57,14 & $\begin{array}{r}(89) \\
(8) \\
(36) \\
(4) \\
(1) \\
\end{array}$ & $\begin{array}{r}28,89 \\
2,59 \\
11,76 \\
1,29 \\
0,32 \\
\end{array}$ & 44,80 \\
\hline Punzon: & 2 & 0,64 & 2,04 & 2,43 & 2 & 0,64 & 1,25 & 1,65 & - & - & - & - & 4 & & 1,29 \\
\hline Plat & 6 & 1,94 & 6,12 & 7,31 & 2 & 0,64 & 1,25 & 0,64 & - & - & - & - & 8 & & 2,59 \\
\hline Miestal & 4 & 1,29 & 4,08 & 4,87 & 6 & 1,94 & 3,77 & 4,95 & 2 & 0,64 & 3,84 & 4,76 & 12 & & 3,89 \\
\hline AรE) & 2 & 0,64 & 2,04 & 2,43 & 6 & 1,94 & 3,77 & 4,95 & 5 & 1,61 & 9,61 & 11,90 & 13 & & 4,22 \\
\hline 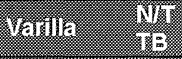 & $\begin{array}{ll}9 & 12 \\
3 & 12 \\
\end{array}$ & 3,88 & 12,24 & 14,63 & $\begin{array}{ll}13 & 26 \\
13\end{array}$ & 8,41 & 16,35 & 21,48 & $\begin{array}{ll}7 & 11 \\
4 & 11 \\
\end{array}$ & 3,55 & 21,15 & 26,19 & $\begin{array}{l}(29) \\
(20)\end{array}$ & $\begin{array}{l}9,41 \\
6,49 \\
\end{array}$ & 15,90 \\
\hline Fun woreso: & 2 & 0,64 & 2,04 & 2,43 & 5 & 1,61 & 3,14 & 4,13 & - & - & - & - & 7 & & 2,27 \\
\hline Alfsterer. & 3 & 0,97 & 3,06 & 100 & - & - & - & - & - & - & - & - & 3 & & 0,97 \\
\hline Ginge) & - & - & - & - & 1 & 0,32 & 0,62 & 100 & - & - & - & - & 1 & & 0,32 \\
\hline Allsablersties & - & - & - & - & - & - & - & - & 1 & 0,32 & 1,92 & 100 & 1 & & 0,32 \\
\hline valacoraina & - & - & - & - & 1 & 0,32 & 0,62 & 20 & - & - & - & - & 1 & & 0,32 \\
\hline Diente: & 1 & 0,32 & 1,02 & 100 & 4 & 1,29 & 2,51 & 80 & 4 & 1,29 & 7,69 & 100 & 9 & & 2,92 \\
\hline Patera & 1 & 0,32 & 1,02 & 100 & 1 & 0,32 & 0,62 & 50 & - & - & - & - & 2 & & 0,64 \\
\hline Tensor & - & - & - & - & 1 & 0,32 & 0,62 & 50 & - & - & - & - & 1 & & 0,32 \\
\hline Then: & 2 & 0,64 & 2,04 & 50 & - & - & - & - & - & - & - & - & 2 & & 0,64 \\
\hline Oosulla: & 1 & 0,32 & 1,02 & 25 & - & - & - & - & - & - & - & - & 1 & & 0,32 \\
\hline Escaloula. & - & - & - & - & 1 & 0,32 & 0,62 & 33,33 & - & - & - & - & 1 & & 0,32 \\
\hline 1701.0 & 1 & 0,32 & 1,02 & 25 & 1 & 0,32 & 0,62 & 33,33 & - & - & - & - & 2 & & 0,64 \\
\hline Vamile sto & - & - & - & - & - & - & - & - & 1 & 0,32 & 1,92 & 100 & 1 & & 0,32 \\
\hline Fivinglars & - & - & - & - & 1 & 0,32 & 0,62 & 33,33 & - & - & - & - & 1 & & 0,32 \\
\hline 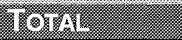 & 98 & 31,71 & & & 159 & 51,45 & & & 52 & 16,82 & & & 309 & & \\
\hline
\end{tabular}

\section{1. $\mathrm{N} \cdot 3$}

La industria ósea de la unidad superior del Estrato III comprende 98 piezas, 91 de las cuales -un 92,85\% - constituyen morfotipos (Gráficos 1-2; tabla 1). En contrapartida, contamos con un número reducido de matrices $-2,04 \%$ - y elementos en proceso de elaboración $-5,10 \%-$. Junto a la industria ósea encontramos 25 fragmentos de fauna con evidentes marcas de descarnado -14 costillas y 10 diáfisis- y de despellejamiento -1 mandíbula-.

como la supuesta para estaciones magdalenienses tan emblemáticas como la cercana Cueva de La Paloma. La industria ósea de su Nivel 4, el más fértil desde un punto de vista arqueológico, cuenta con 114 piezas, a las que se sumarían 7 mencionadas por Hernández Pacheco hoy perdidas y una pieza decorada de procedencia incierta asignada a este mismo Nivel 4 (Chapa y Martínez Navarrete 1977; Martínez Navarrete y Chapa 1980: 154). Por el contrario, Corchón (1986: 471-472, fig. 197.5) duda si la pieza en cuestión es originaria de La Cuevona de Ribadesella o quizá de La Paloma. Por otra parte, la industria ósea de Oscura de Ania cuenta con una representación consistente de morfotipos escasos en el Magdaleniense superior cantábrico, como las varillas con relieve tuberculado (Adán et al. e. p. b).
Se trata de una colección a un tiempo especializada, pues concentra la mayoría de sus elementos en dos categorías tipológicas, pero relativamente variada si prestamos atención a la cantidad de morfotipos y grupos tipológicos representados. El rasgo principal del conjunto es el abrumador predominio de apuntados: 82 ejemplares, un 83,67\% sobre el total. Los morfotipos de este grupo con mayor número de efectivos son azagaya y varilla, disponiendo una proporción sensiblemente menor de microazagayas, arpones, puntas, punzones y agujas. En cuanto al resto de los grupos morfológicos, sólo reúnen 9 efectivos, un exiguo $9,18 \%$ sobre la totalidad del conjunto. Es relativamente significativa la presencia de biselados y testimonial la de romos y perforados. El conjunto lo completan 4 objetos decorados en soportes no elaborados.

En total, entre soportes conformados y no conformados, este Nivel cuenta con 21 manifestaciones de arte mueble: el 21,42\% de la colección, proporción más baja que en yacimientos magdalenienses de la zona como la Cueva de La Paloma. 


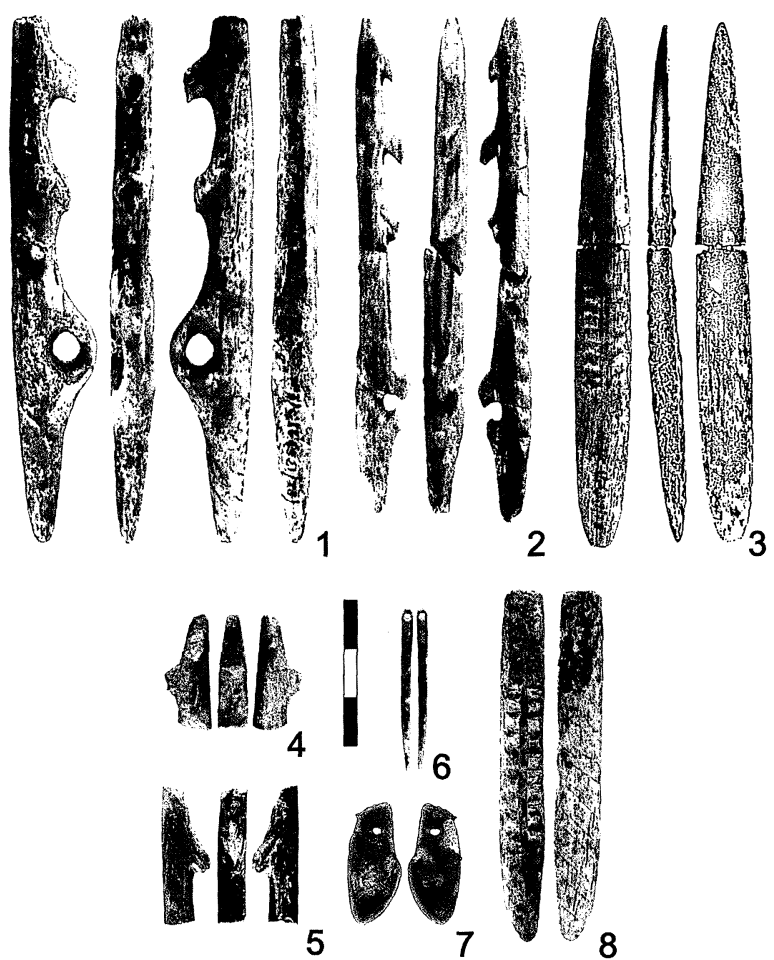

Fig. 6: Muestra de la industria ósea del Nivel 3a. 1-2, 4-5: arpones; 3, 8: varillas con decoración dorsal tuberculada; 6 : aguja; 7: colgante sobre canino atrófico de ciervo.

Los niveles 4 y 6 del mismo cuentan con un $33 \%$ y un 50\% de los objetos decorados (Martínez Navarrete y Chapa 1980: 198-199). Bien es cierto que, aún reconociendo la meticulosidad de los métodos de Hernández Pacheco en el contexto de su época, la colección ósea de La Paloma se intuye más seleccionada que la de Oscura de Ania (Corchón 1995a).

La mayoría de las decoraciones, de tipo no figurativo, se documentan sobre piezas apuntadas, algo que no debería sorprender, pues es el grupo más nutrido. Concretamente, se concentran en los dos morfotipos más numerosos: azagayas (11) y varillas (3). Siguen, con un representante decorado cada uno, arpón, punta de cuerna y punzón. A ello hemos de sumar los cuatro soportes no conformados mencionados anteriormente: 1 costilla, 2 pitones y 1 tubo.

En cuanto a las técnicas de manufactura ósea, hemos documentado apuntamientos por el desarrollo de planos; por refuerzo del apuntamiento natural obtenido de las astillas y aplicando recortes a partir de planos escalonados para, finalmente, regularizar las superficies mediante incisiones longitudinales. Casi todas estas formas de trabajo se gene- ralizan a partir del Magdaleniense medio y abundan a finales del Tardiglaciar (Adán Álvarez 1997: 329). La mayoría de las piezas se completaron con la combinación técnica aserramiento/pulimento (As/Pu a partir de este momento), propia de las primeras fases del Magdaleniense asturiano. Cuando menos, eso parece indicar el registro de las Cuevas de Las Caldas y Cueto de La Mina (Posada, Llanes). No obstante, también se documenta en yacimientos del Magdaleniense superior inicial. Tal es el caso de la Cueva de Tito Bustillo, en Ribadesella (Adán Álvarez 1997: 324). Esta diversidad de técnicas de fabricación contrasta con la notable homogeneidad en la selección de materia prima: la mayor parte del conjunto se fabricó en asta, existiendo pocos ejemplos de diáfisis utilizadas como matrices (p.e. un punzón sobre metacarpo de cabra o las agujas).

\section{- Azagayas}

Este morfotipo monopoliza 45 ejemplares, un $54,87 \%$ sobre el total de apuntados. La totalidad de las secciones son circulares o de tendencia circular. Sólo 12 azagayas -un 26,66\% - conservan su extremo proximal, aunque presentan una notable diversidad morfológica: 5 monobiselados $(41,66 \%) ; 5$ biseles dobles $(41,66 \%)$ y 2 proximales romos o redondeados $(16,66 \%)$. Dentro de las azagayas de esta capa destacan 2 ejemplares -un $4,44 \%$ sobre el total de este morfotipo- con decoración en relieve tuberculado. Esta colección de azagayas es muy homogénea en cuanto a la técnica de fabricación y la materia prima utilizada (asta en todos los casos). Los ejemplares que conservan su extremo distal presentan superficies de apuntamiento amplias -próximas a los $26 \mathrm{~mm}$ de longitud-, rasgo tecnológico que comienza a generalizarse desde las fases iniciales del Magdaleniense asturiano (Adán Álvarez 1997: 330, 335). Además de As/Pu, para el acabado de las piezas se aplicaron técnicas como el cepillado (C) o la combinación aserramiento/abrasión (As/Ab). Bien es cierto que ésta se documenta de una forma que casi podría definirse como testimonial: Tan sólo se aprecia en 5 ejemplares -un 11,11\% sobre el total de azagayas-. Entre las azagayas que conservan el extremo distal se ha constatado la reutilización de piezas con puntas romas, generalmente mediante el recorte escalonado de dicha extremidad. 


\section{- Varillas}

Este morfotipo cuenta con 12 ejemplares, un $14,63 \%$ sobre el total de apuntados. El conjunto es, por otra parte, muy homogéneo, pues todos los especímenes cuentan con proximales redondeados; fueron realizados sobre asta y se finalizaron por medio de la combinación As/Pu. Las superficies de apuntamiento alcanzan longitudes que rondan los $20 \mathrm{~mm}$, aunque son abundantes los ápices distales casi romos. Destacan tres ejemplares con relieve tuberculado sobre la cara dorsal (Figs. 6.3 y 6.8). En un caso, ha podido apreciarse que la decoración se realizó con anterioridad a finalizar la conformación de la pieza (Fig. 7.6).

\section{- Microazagayas}

El conjunto cuenta con 5 microazagayas $(6,09 \%$ de apuntados). Todas ellas realizadas sobre asta; 3 ejemplares se finalizaron por medio de la técnica $\mathrm{As} / \mathrm{Pu}$ y 2 por medio de As/Ab. Algunas de las ellas son piezas reutilizadas, pues se trata de puntas, posiblemente rotas, de unos $25 \mathrm{~mm}$ de longitud, con una base recortada para su enmangue (Fig. 7.1) que alcanza los 9 mm (Adán Álvarez 1997: 340). Sólo en un caso se ha identificado una terminación apuntada. Este tipo de piezas recortadas se documentan desde el Solutrense (ibidem), pero parece

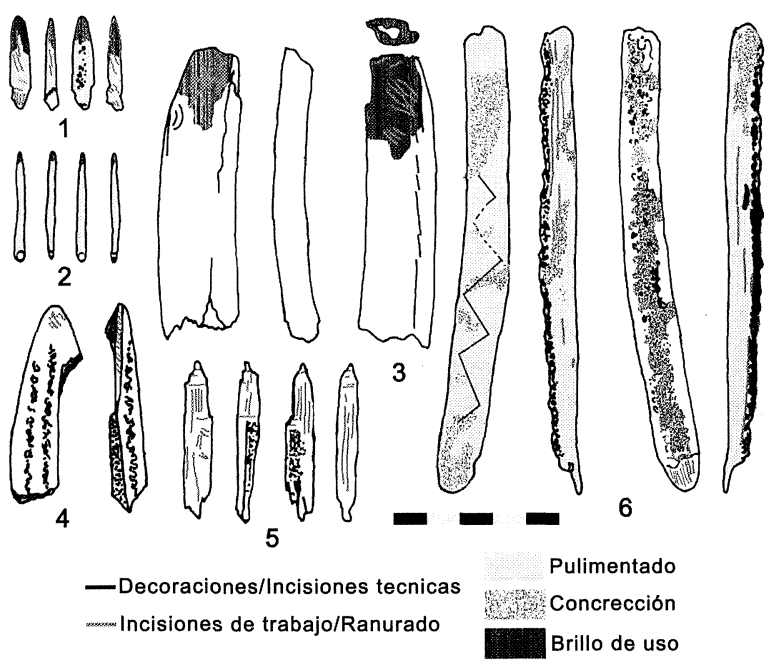

Fig. 7. Muestra de la industria ósea del Nivel 3a (dibujo técnico). 1: microazagaya; 2 : aguja; 3 : alisador sobre costilla; 4: matriz de asta; 5: mesial; 6: varilla sin finalizar con decoración lineal incisa dorsal. generalizarse a finales del Tardiglaciar, identificándose en Asturias en el Magdaleniense de las Cuevas de La Paloma; La Lloseta (Ardines, Ribadesella); Tito Bustillo; Cueto de la Mina y La Riera (Posada, Llanes).

\section{- Arpones}

Esta capa cuenta con 4 arpones, el 4,87\% de los apuntados. Dos de ellos son fragmentos distales que conservan la raíz del primer diente (Figs. 6.4-6.5). Los dos restantes cuentan con protuberancia basal perforada (Figs. 6.1-6.2). En general, los 4 ejemplares muestran técnicas de fabricación y morfología muy similares a las apreciadas en los horizontes industriales asturianos donde este morfotipo comienza a documentarse (Adán Álvarez 1997: 332): la combinación $\mathrm{As} / \mathrm{Pu}$; fuste de sección circular; dientes bien separados del vástago y protuberancia perforada dentro del tercio basal de la pieza.

\section{- Otros apuntados}

El capítulo de apuntados se completa con 6 puntas de cuerna; 4 mesiales de agujas/biapuntados/ anzuelos; 2 agujas y 2 punzones. Todas las puntas de cuerna fueron regularizadas mediante la combinación $\mathrm{As} / \mathrm{Pu}$, como es habitual desde las fases iniciales del Magdaleniense para este morfotipo. La totalidad de los mesiales fueron fabricados en diáfisis mediante As/Pu. Para la fabricación de las agujas se emplearon astillas de diáfisis, sobre las que también se aplicó la combinación As/Pu (Figs. 6.6 y 7.2). Los orificios, de $1 \times 1 \mathrm{~mm}$, fueron obtenidos mediante incisión giratoria. Una de las dos piezas muestra claras evidencias de constituir una reutilización. Los 2 están fabricados con diáfisis, si bien uno de ellos se realizó sobre un metacarpo de cabra reutilizado tras haber servido de matriz. Este cómputo de apuntados se cierra con 2 piezas en proceso de conformación.

\section{- Otros grupos tipológicos}

Esta capa sólo cuenta con 9 piezas no apuntadas. Tres de las mismas son biselados, alisadores si atendemos a las huellas de uso. Dos fueron fabricados en costillas y otro en asta. Contamos con un representante del grupo de los romos, que hemos clasi- 
ficado como paleta. Fabricada sobre asta, fue conformada mediante $\mathrm{As} / \mathrm{Pu}$ y en su superficie pueden apreciarse brillos de uso. La colección ósea de la capa se completa con un colgante (Figura 6.7) -un canino atrófico de ciervo perforado- y 4 muestras de arte mueble en soportes no elaborados: 1 costilla, 2 pitones y 1 tubo, todos ellos con decoración lineal incisa.

\section{2. $\mathbf{N} \cdot 3 \mathbf{a}$}

La industria ósea de N·3a consta de 159 ejemplares, un $51,45 \%$ sobre el total del depósito magdaleniense del yacimiento (Gráficos 1-2; tabla 1). Sólo un $16,98 \%$ (27 ejemplares) son elementos en proceso de elaboración: 8 matrices; 7 candiles y 12 varillas de extracción. El resto, 132 piezas (un 83,01\%), lo constituyen morfotipos plenamente acondicionados. Junto a esta industria ósea se seleccionaron 29 restos de fauna con marcas de carnicería: 13 costillas, 13 diáfisis y 2 escápulas con trazas de descarnado y 4 fragmentos de fractura para la extracción de grasa. La distribución de morfotipos por grupos tipológicos es muy similar a la observada en la capa anterior. El más numeroso es el de apuntados, con 121 efectivos (un $91,66 \%$ del conjunto manufacturado), la mayoría acaparados por azagayas y varillas. El conjunto lo completan representantes de los grupos de biselados; romos y perforados, además de decorados no utilitarios. Parece tratarse, pues, de un conjunto relativamente especializado y de carácter eminentemente utilitario.

El capítulo de arte mueble cuenta con 27 ejemplares (un 16,98\% sobre el total) entre soportes transformados y no transformados: 11 azagayas; 13 varillas; 1 apuntado; 1 escápula y 1 hueso de ave. La mayoría de estas decoraciones son simples incisiones laterales cortas o semicirculares. No obstante, 12 varillas cuentan con relieve tuberculado en sus caras dorsales, en ocasiones combinados con acanaladuras centrales. En la Cornisa Cantábrica este motivo cuenta con más ejemplos en el Magdaleniense medio que en el superior (Adán Álvarez 1997: 345; González Sainz 1989a: 228).

Casi todos los apuntados fueron realizados en asta y documentan técnicas de apuntamiento diversas. Una de las mejor representadas es el apuntamiento a partir de varios planos. Este método de trabajo, aunque en Asturias comienza a apreciarse en yacimientos solutrenses, se prodiga durante el Magdaleniense inferior $y$, fundamentalmente, el

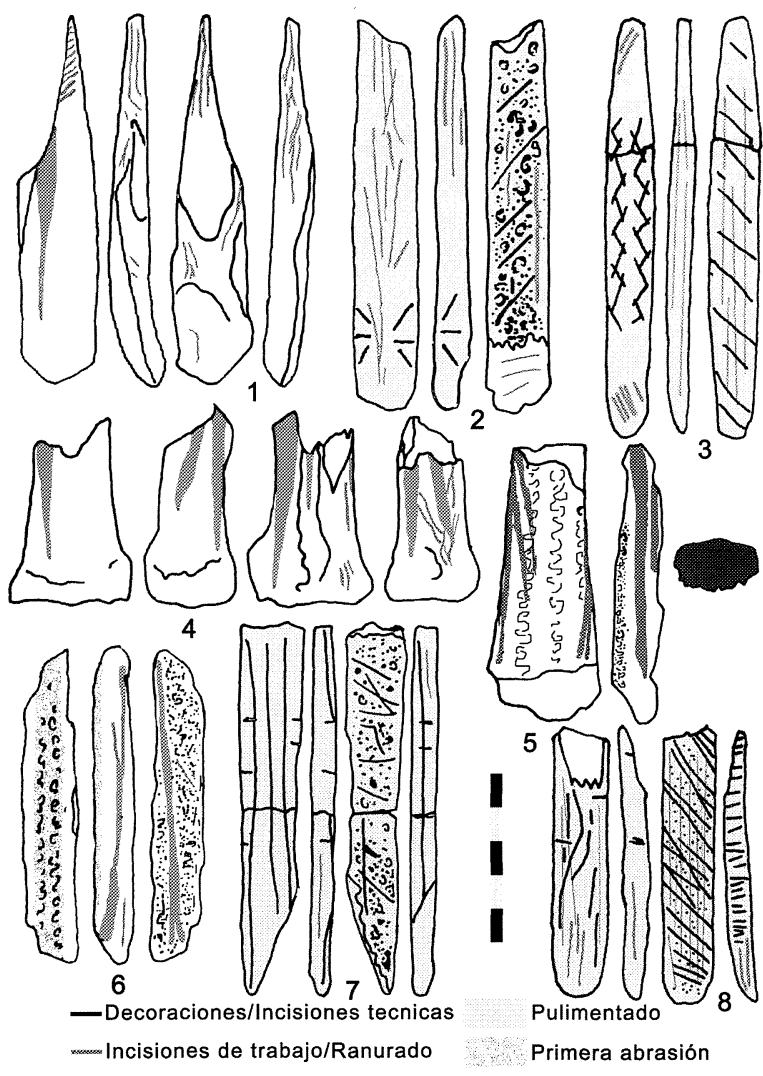

Fig. 8. Muestra de la industria ósea de los Niveles 3a (1-6) y 3b (7-8). 1: punzón; 2, 7-8: varilla con decoración lineal incisa dorsal; 3 : varilla con decoración dorsal tuberculada; 4: matriz ósea para extracción de agujas; 5: matriz de asta para la extracción de varillas y azagayas; 6 : varilla inacabada; 7-8 varillas con decoración lineal incisa dorsal.

medio (Adán Álvarez 1997: 329). También hemos documentado algún apuntamiento obtenido por medio del trabajo sobre ambos laterales, procedimiento que comienza a ser utilizado durante el Magdaleniense medio y se generaliza en el transcurso del Magdaleniense superior y el Aziliense (ibidem). Entre la industria ósea de este nivel hemos constatado la presencia de piezas - una varilla y un arpón- donde podría apreciarse el aprendizaje de alguien inexperto en la fabricación de utillaje óseo, aspecto este que trataremos mas adelante.

La materia prima utilizada con mayor profusión es el asta, siendo la técnica de extracción más utilizada el ranurado de varillas o esquirlas (Figs. 8.58.6). Algunas de estas cuentan con señales de abrasión previa (Fig. 8.6). También se han documentado matrices sobre tibias de cabra; sobre proximun de metacarpo de cabra, empleadas específicamente

T. P., 59, n. $^{\circ} 2,2002$ 
para la obtención de agujas (Fig. 8.4), y sobre hueso de ave. Contamos con un colmillo de jabalí con marca de golpeo que sugiere su empleo para extraer una varilla. Los paralelos más cercanos se ubican en el episodio Alleröd/Cantábrico VIII (ibidem: $325)$.

\section{- Azagayas}

El Nivel 3a cuenta con 69 azagayas, el 57,02\% de todos los apuntados de esta capa. Uno de los representantes de este morfotipo cuenta con relieve tuberculado en su cara dorsal. En cuanto a los extremos proximales, 23 ejemplares (un 33,33\% sobre el total de azagayas) lo conservan. Los mismos cuentan con una notable homogeneidad tipológica: 18 biseles dobles $-78,26 \%-; 2$ biseles simples $-8,69 \%-; 1$ aplastamiento basal $-4,35 \%$ - y 2 bases romas o redondeadas $-8,69 \%-$. En varios proximales se aprecia la existencia de incisiones de uso. Esta identidad también se manifiesta en las secciones (circulares o de tendencia circular, según casos); en la robustez de los fustes y en las técnicas de fabricación. El 97,10\% de las azagayas (67 especímenes) fueron conformadas mediante As/ $\mathrm{Pu}$. El resto de métodos de trabajo documentados tienen una presencia residual, con un $1,45 \%$ de piezas finalizadas por medio de As/Ab e idéntico porcentaje de Cepillado (un ejemplar, respectivamente). En cuanto a los apuntamientos, cuentan con longitudes que se sitúan en torno a los $20 \mathrm{~mm}$, media que se documenta en Magdaleniense medio y superior (Adán Álvarez 1997: 335).

\section{- Varillas}

El segundo morfotipo mejor representado en esta capa es la varilla, con 26 ejemplares, un $21,48 \%$ sobre el total de apuntados. Es llamativa la alta proporción de especímenes con dorsales con decoración en relieve tuberculado (Fig. 8.3): un $50 \%$ (13 piezas). Todas las varillas de esta capa fueron elaboradas sobre asta, extraída mediante ranurado (Figs. 8.5-8.6). La conformación definitiva de las piezas recurrió a As/Pu (Figs. 8.28.3). En la cara ventral de 9 ejemplares se aprecian huellas de uso, acompañadas de incisiones oblicuas. En general, las bases son romas ( 9 casos), documentándose un solo caso de extremidad proximal apuntada.

\section{- Arpones}

Esta capa ha proporcionado un único arpón, de características un tanto especiales. Se trata de un ejemplar en proceso de elaboración con un solo diente y sección cuadrangular, a cuya base aún no se le había dado forma cuando se desechó (Fig. 9). La singularidad de su morfología bien pudiera atribuirse a la amplia variabilidad de soluciones ensayadas en un momento previo a la estandarización de este morfotipo, como ha señalado González Sainz (1995: 167). No obstante, el análisis técnico de esta pieza, como el de una varilla en fabricación de este mismo N.3a (Fig. 8.6), permite concluir que, de haberse finalizado, hubiera tenido escasa o nula utilidad práctica. Esta circunstancia sugiere que estos objetos constituyen el ensayo de técnicas de trabajo sobre asta por parte de alguien con poca pericia en la tarea (Adán et al. e. p. b: nota 39). Algunos autores han señalado la presencia en el registro de objetos de fabricación defectuosa o imitaciones de útiles no muy efectivas, como son estos casos y el de un arpón realizado en costilla de la Cueva de Los Azules I [Contranquil, Cangas de Onís] (Adán Álvarez 1997: 120, 332), que podrían ponerse en relación con tanteos de manufactura. Politis (1998) ha propuesto que este tipo de elementos constituiría una evidencia arqueológica del adiestramiento infantil.

\section{- Otros apuntados}

El grupo morfológico de apuntados cuenta con 4 microazagayas; 6 mesiales de aguja/anzuelo/biapuntado; 6 agujas; 2 punzones (Fig. 8.1); 2 puntas de cuerna y 5 apuntados en proceso de elaboración. Las primeras fueron fabricadas siguiendo un método similar al empleado en las microazagayas documentadas en la capa anterior, si bien algunas bases se conformaron de forma distinta: 2 casos cuentan con proximal en bisel doble, lo que les asemeja a ejemplos documentados en las Cuevas de La Riera y Balmori (Balmori, Llanes), y otro con un único bisel, como algunos ejemplares de Cueto de $\mathrm{La}$ Mina y de las Cuevas de La Paloma y la Riera (Adán Álvarez 1997: 340).

Las 6 agujas del conjunto fueron fabricadas de idéntica forma que los ejemplares de la capa superior: en astillas de diáfisis, mediante As/Pu y empleando incisiones giratorias para obtener perforaciones (entre 1,5 y $1 \mathrm{~mm}$ de diámetro). Uno de los 
especímenes es un caso evidente de reutilización por rotura del orificio. En cuanto a los mesiales, todos ellos se fabricaron siguiendo el método descrito para las agujas, exceptuando la secuencia relativa a la obtención de perforaciones. Por su parte, las 2 puntas sobre cuerna regularizada también fueron realizadas mediante $\mathrm{As} / \mathrm{Pu}$. Un caso cuenta con base de doble bisel y la otra de bisel simple. Los 2 punzones identificados fueron conformados en diáfisis, si bien uno de ellos constituye una reutilización de matriz (Fig. 8.1).

\section{- Otros grupos tipológicos}

El grupo de biselados únicamente está representado por un cincel en asta quie presenta brillos y trazas de desgaste relacionados con su uso. En cuanto al de romos, hemos identificado 2 piezas. Una de ellas es una paleta sobre asta con un extremo apuntado; la otra es un tensor en metápodo con marcas de uso.

El grupo de perforados cuenta con 4 colgantes: 2 sobre caninos atróficos de ciervo, con orificios obtenidos por aserramiento giratorio (media de $2 x$ $3 \mathrm{~mm}$ ); 1 incisivo de cérvido con perforación lateral $(2 \times 3 \mathrm{~mm})$ y 1 concha de Hinia reticulata, con orificio logrado mediante abrasión (plano de $6 \times 6$ $\mathrm{mm}$ y hueco de $3 \times 3 \mathrm{~mm}$ ). El conjunto del N.3a se completa con 3 muestras de arte mueble sobre soportes no elaborados: 1 escápula; 1 tubo óseo y 1 esquirla apuntada.

La pieza más llamativa es un fragmento de escápula de cérvido $(92 \times 28 \times 9 \mathrm{~mm})$ con incisiones de limpieza y varios motivos decorativos. En su cara superior se ha descrito una cabeza de cierva mirando hacia la izquierda, figura sobre la que se ha afirmado que "tal y como se aprecia en la actualidad, es una rectificación o aprovechamiento de otra anterior, también difícil de identificar" (Pérez Pérez 1992: 626). En este campo decorativo también pueden apreciarse motivos lineales en paralelo (10), algunos "signos aflecados", un "claviforme" e incisiones oblicuas múltiples. La cara inferior o

(10) En el presente trabajo utilizamos la caracterización de los motivos iconográficos publicada por Pérez Pérez (1992) en su estudio de la pieza. No obstante, nuestra revisión pormenorizada con lupa binocular de la pieza aún está por realizar y nuestra interpretación bien pudiera diferir de la propuesta por el autor citado. En cualquier caso, es destacable que el fragmento de escápula en cuestión cuenta con diversos trazos y combinaciones lineales que no responden ni a marcas de descarnado ni a huellas tafonómicas. cóncava, cuenta con una cierva de cuerpo entero orientada hacia la derecha y rodeada por diversos signos (Fig. 5).

\section{3. $\mathbf{N} \cdot 3 \mathrm{~b}$}

La industria ósea registrada en N.3b cuenta con un número sensiblemente menor de efectivos que los dos precedentes: 52 ejemplares, un $16,82 \%$ sobre el total del conjunto óseo magdaleniense (Gráficos 1-2; tabla 1). Los morfotipos completos reúnen 48 especímenes $(92,3 \%)$, completando la colección 2 matrices ( 1 matriz ósea y 1 pitón con incisiones de trabajo) y 2 varillas en proceso de elaboración. Junto a este conjunto, los excavadores del yacimiento seleccionaron una diáfisis con marcas de carnicería. El grupo tipológico mejor representado es el de los apuntados: acumula 42 piezas, el $87,5 \%$ de los morfotipos. Azagaya (24) y varilla (11) son los tipos mejor representados, seguidos de aguja (5) y biapuntado (2). La colección se completa con 4 perforados y un solo representante del grupo de biselados. Se trata, pues, de un conjunto altamente especializado, a juzgar por estos datos.

La materia prima más utilizada en N.3b es el asta, con el ranurado como técnica predominante de extracción. Buena parte de los apuntamientos se obtuvieron por medio de planos o recurriendo a las incisiones longitudinales. Ambas técnicas caracterizan el Magdaleniense medio, pero no dejan de documentarse a lo largo de finales del Tardiglaciar (Adán Álvarez 1997: 329).

\section{- Azagayas}

La azagaya es el morfotipo mejor representado en la muestra, con 24 ejemplares (el $57,14 \%$ de apuntados). Sólo uno de ellos cuenta con decoración. Por el contrario, la colección de azagayas de este subnivel es la que, en términos proporcionales, cuenta con más extremos distales conservados: un $58 \%$ (14 piezas). La base con bisel doble domina abrumadoramente, con 13 representantes $(92,86 \%)$ frente a un único ejemplar monobiselado $(7,14 \%)$. Todos los biseles conservados cuentan con huellas de uso. Esta homogeneidad tipológica se extiende también a las secciones, circulares o de tendencia circular, y a las técnicas de fabricación. Prácticamente la totalidad de las piezas fueron realizadas en asta y acabadas por medio de As/Pu. La excepción

T. P., 59, n. ${ }^{\circ} 2,2002$ 
a esta tónica es un ejemplar conformado mediante Cepillado. Como en N.3a, los apuntamientos alcanzan una longitud media de $20 \mathrm{~mm}$.

\section{- Varillas}

Como en los dos subniveles superiores, en $\mathrm{N} \cdot 3 \mathrm{~b}$ la varilla es el segundo morfotipo en número de ejemplares, con 11 piezas (un $26,19 \%$ sobre el total de apuntados). Todos ellos con bases romas (Fig. 8.8). Un $36,36 \%$ (4 especímenes) cuenta con decoración dorsal en forma de relieve tuberculado. Atendiendo a aspectos técnicos, todas las varillas fueron manufacturadas sobre asta. La conformación se. realizó utilizando la combinación As/Pu. Tres de las piezas fueron sometidas a la acción del fuego. Seis especímenes cuentan con incisiones ventrales de enmangue (Figs. 8.7-8.8).

\section{- Otros morfotipos}

El grupo de apuntados se completa con 5 agujas y 2 fragmentos mesiales de agujas/anzuelos/biapuntados. Tanto unas como otras fueron manufacturadas en astillas de diáfisis por la combinación de $\mathrm{As} / \mathrm{Pu}$. En cuanto a las agujas, los ojos $(1 \times 1 \mathrm{~mm}$ de media) se realizaron por incisiones giratorias. Uno de los ejemplares de aguja fue reutilizado y otro muestra brillos de uso en el orificio.

Sólo contamos con 6 ejemplares fuera del grupo de apuntados, un 12,5\% sobre la colección. Uno de ellos es un biselado, un alisador/cincel fabricado en pitón de ciervo y otro una varilla de asta sin trabajar pero decorada. El resto pertenece al grupo de perforados. Se trata de 4 colgantes: 1 plaquita de arenisca de forma elíptica (11) y 3 caninos atróficos de ciervo. Estos últimos cuentan con orificios -media de $2 \times 3 \mathrm{~mm}$ - obtenidos por aserramiento giratorio.

\subsection{La industria ósea magdaleniense de Cueva Oscura de Ania: caracterización general}

Una de las características del conjunto estudiado es que la práctica totalidad de las piezas que la

(11) Aunque esta pieza se realizara sobre una materia prima lítica, su condición de colgante nos ha llevado a situarla entre la industria ósea para no descontextualizarla del resto de los ejemplares de este morfotipo que forman parte de la colección de Cueva Oscura de Ania. integran son morfotipos completamente elaborados, siendo discreta la representación de matrices y elementos en proceso de elaboración (Gráficos 1-2; tabla 1). Por otra parte, se trata de una colección muy homogénea desde un punto de vista tipológico (Adán et al. e. p. b). El grupo dominante es el de apuntados -con una notable concentración de elementos en las categorías "azagaya" y, en segundo lugar, "varilla"- y una presencia prácticamente residual de biselados y romos. Agujas, arpones y microazagayas cuentan con porcentajes relativamente consistentes, con notoria concentración de las primeras en $\mathrm{N} \cdot 3 \mathrm{a}$ y N.3b y de los segundos en N.3. La microazagaya, es un morfotipo que en el occidente de la Cornisa Cantábrica se documenta desde el Solutrense (Adán Álvarez 1997: 340), aunque parece generalizarse en momentos avanzados del Tardiglaciar.

Entre las técnicas de fabricación documentadas, han podido apreciarse algunas propias del Magdaleniense medio asturiano. Una de ellas es el apuntamiento a partir de varios planos, cuyo uso empieza a documentarse en este mismo horizonte industrial. Lo mismo puede asegurarse del apuntamiento trabajado sobre ambos laterales. Bien es cierto que en N.3 se constatan técnicas de conformación generalizadas a partir del Magdaleniense medio que proliferan a finales del Tardiglaciar junto a algunas formas de acabado documentadas durante el Magdaleniense superior (Adán Álvarez 1997: 329).

\section{- Arpones}

Quizá la diferencia principal entre los tres niveles sean los arpones, si bien su presencia es reducida en todo el paquete. El número total de especímenes es 5 , aumentando su representación de base a techo: 0 en N.3b; 1 en N.3a (la capa arqueológica con una industria ósea más nutrida) y 4 en $\mathrm{N} \cdot 3$, lo que constituye una presencia relativamente significativa $(4,12 \%)$. Podría argumentarse que la ausencia de arpones en N.3b supusiera una desviación estadística, consecuencia del reducido número de elementos que integran este conjunto óseo. Sin embargo, también es plausible que su aparición en N.3a sea una intrusión desde la capa superior por procesos de bioturbación. Un dato a favor de esta interpretación es la abundancia de restos de conejo detectada en el 
$\mathrm{N} \cdot 3 \mathrm{a}$ (12), concentrada en uno de los cuadros más cercanos a la entrada de la Cueva. Más allá de otras consideraciones, la inexistencia de marcas de acción antrópica previene sobre la posibilidad de tanatocenosis en madriguera a la hora de interpretar su presencia en el espectro faunístico del Nivel.

\section{- Azagayas}

En cuanto a las azagayas, la morfología de todos los especímenes documentados es muy similar: secciones circulares y de porte generalmente esbelto. Las únicas diferencias apreciables entre los tres niveles es la configuración de los extremos proximales conservados. En N.3b domina el doble bisel frente a la tipología monobiselada; en N.3a se mantiene este predominio del bisel doble, pero también cuenta con la mayor variabilidad de sistemas de enmangue de toda la secuencia. En N.3 esta tendencia comienza a invertirse, con un porcentajes equilibrados de biseles simples y dobles (un 46,66\% para ambas morfologías) y un incremento apreciable de piezas con bases romas o redondeadas $(16,66 \%)$, así como una ligera disminución de la longitud media en los especímenes completos. El dominio de biseles dobles coincide con aquellos niveles donde los proximales conservados tienen mayor incidencia, los dos inferiores dentro del depósito magdaleniense de Cueva Oscura.

\section{- Varillas}

A su vez, la presencia de varillas es constante y consistente en toda la secuencia, con bastantes ejemplares decorados. Es llamativa la abundancia de especímenes con relieve tuberculado dorsal - con una mayor concentración en N.3b- pues Cue-

(12) El conjunto de huesos identificables apenas alcanza el $4 \%$ del total conservado en el MAA: Ciervo $(21,7 \%$ en $\mathrm{N} \cdot 3 \mathrm{a}$ y $75,6 \%$ en $\mathrm{N} \cdot 3 \mathrm{~b}$ ); cabra $(21,7 \%$ en $\mathrm{N} \cdot 3$ a y $12,5 \%$ en $\mathrm{N} \cdot 3 \mathrm{~b})$; bóvido ( $12,9 \%$ en N.3a y $7,5 \%$ en N.3b); corzo ( $2 \%$ en N.3a). Destaca la abundancia de conejo en N.3a $(41,4 \%)$ siendo casi inexistente en $\mathrm{N} \cdot 3 \mathrm{~b}$ (1 resto). La mayor parte de este material óseo presenta una alto índice de fragmentación y rodamiento. El estudio de Diego J. Álvarez Láo ha documentado que el conjunto óseo del N.3 (N.3a y N.3b) conservado en el MAA cuenta mayoritariamente con restos que no superan los $30 \mathrm{~mm}$ (de 10.908 vestigios del cuadro 1c, 9.528 no alcanzan estas dimensiones). Esta circunstancia impidió una lectura clara de la mayor parte de las marcas de trabajo, sin olvidar que las actuaciones de limpieza y consolidación llevadas a cabo por los investigadores del yacimiento han afectado a la visualización de las huellas de carnicería y conformación técnica. va Oscura cuenta con la mayor colección de este tipo conocida hasta la fecha en la Cornisa Cantábrica: 20 piezas.

\section{ADSCRIPCIÓN Y CONTEXTUALIZACIÓN DE LA INDUSTRIA ÓSEA MAGDALENIENSE DE CUEVA OSCURA DE ANIA}

El análisis de la industria ósea magdaleniense de Oscura de Ania invita a diferenciar dos tecnocomplejos (Adán et al. e. p. b). El primero de ellos (N·3 y quizás algunos elementos de N.3a) está caracterizado por la presencia de arpones, dato que podría interpretarse como representativo de un Magdaleniense superior muy inicial. Por otra parte, las técnicas de fabricación y el repertorio tipológico son muy similares a los documentados en el Magdaleniense medio con arpones de Tito Bustillo (Adán Álvarez 1997: 165-184). El segundo complejo (buena parte de $\mathrm{N} \cdot 3 \mathrm{a}+\mathrm{N} \cdot 3 \mathrm{~b}$ ) documenta formas de trabajo y numerosas varillas decoradas y azagayas de doble bisel, rasgos que no desentonarían en el contexto del Magdaleniense medio evolucionado y el cambio Magdaleniense medio/Magdaleniense superior. En cualquier caso, no podemos soslayar la posibilidad de que en el cuadro 1c algunos elementos arqueológicos de N.3, se mezclaran por bioturbación con el N.3b. Tal parece ser el caso, por ejemplo, del atípico arpón etiquetado como correspondiente a este último subnivel (Fig. 9).

Tradicionalmente se ha considerado que la aparición de arpones constituía un marcador arqueológico del Magdaleniense superior (Adán Álvarez 1997: 334), pero con los datos manejados actualmente resulta problemático delimitar los horizontes Magdaleniense medio y Magdaleniense superior sobre la base de un elemento tan concreto, dada la gran variabilidad formal, escasa pericia técnica y tradición en la preparación de arpones durante el Magdaleniense medio avanzado (González Sainz 1995: 167). Así, la existencia de un arpón en Oscura de Ania N.3a no basta para definir este tramo como un primer horizonte con arpones. Máxime cuando puede representar una intrusión del subnivel inmediatamente superior, como ya señalamos.

Las características un tanto singulares de esta pieza, comentadas en el apartado III.2, se alejan de las apreciadas en contextos del Magdaleniense superior inicial cantábrico como Tito Bustillo 1b-a, Lumentxa D (Lequeitio, Vizcaya) o La Pila 4.3.

T. P., 59, n. ${ }^{\circ} 2,2002$ 


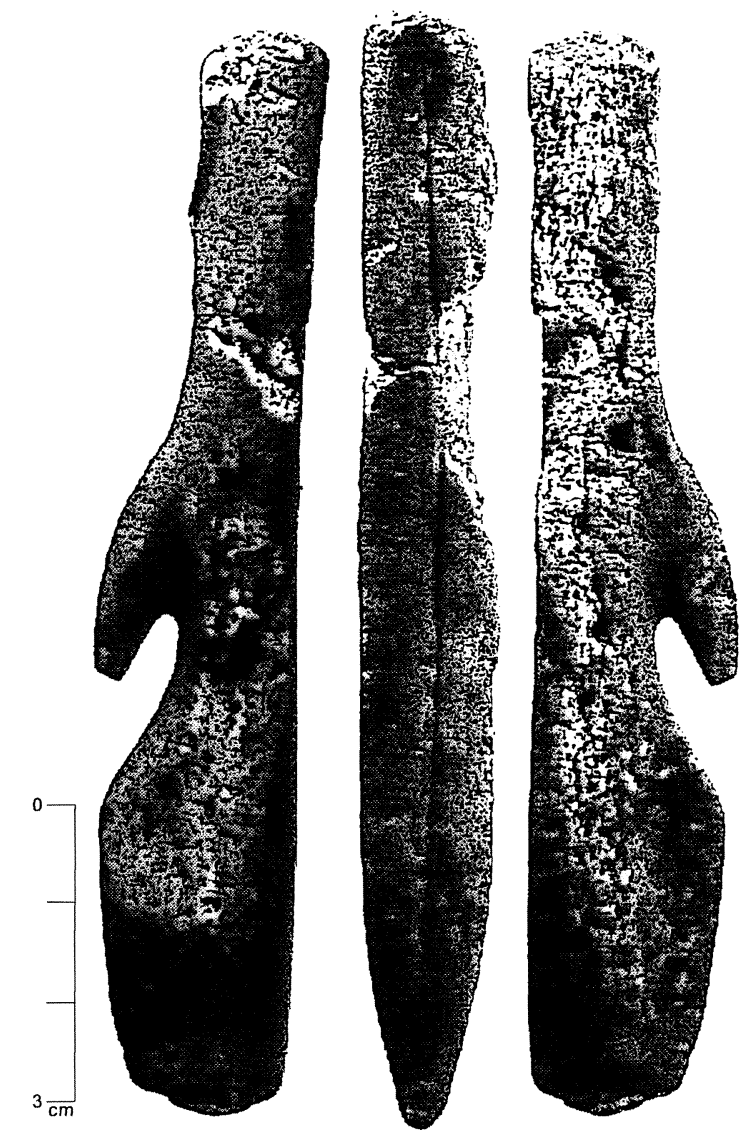

Fig. 9. Arpón. Nivel 3a.

Estos cuentan con secciones de tendencia circular; un número reducido de dientes, ganchudos y bien separados del fuste; bases apuntadas y sistemas de sujeción en forma de protuberancias basales, perforadas en algunos casos (González Sainz 1989a: 253; 1989b: 444-445; 1995: 164-165). Todos ellos rasgos morfológicos que caracterizan los dos arpones mejor conservados de Oscura de Ania N.3 (Figs. 6.1-6.2). Los otros dos especímenes documentados en ese mismo Nivel son fragmentos mesial uno; distal otro-que conservan arranques de dientes y cuya morfología concuerda con la descrita en cuanto a vástago y dentición (Figs. 6.4-6.5).

Por otra parte, no puede descartarse la posibilidad de que en contextos del Magdaleniense medio evolucionado o de transición Magdaleniense medio/superior se documenten arpones muy similares a los que se generalizan en el Magdaleniense superior inicial. Tal es el caso de algún ejemplar documentado en Ermittia II inferior/III superior (Deva, Vizcaya) o Tito Bustillo 1c (González Sainz 1989b: 441; 1995: 167; Esparza y Mújika 1999: 64) o en la propia cuenca del Nalón, como ocurre en Las Caldas III y a techo de La Viña IV superior (Corchón 1994: 256; 1995a: 144; 2000: 496; Fortea Pérez 1989: 430; Esparza y Mújika 1999: 64). El espectro tipológico y las técnicas de manufactura ósea documentados en el tramo N.3b-N.3a de Oscura de Ania tampoco favorecen su adscripción al Magdaleniense superior. En lo relativo al segundo punto, hemos apreciado formas de trabajar el hueso y el asta que se ajustan a las conocidas en los yacimientos asturianos donde se documenta el Magdaleniense medio y el tránsito Magdaleniense medio/Magdaleniense superior (Adán Álvarez 1997).

En cuanto al espectro tipológico, el Magdaleniense medio evolucionado ha venido definiéndose (Corchón 1994: 256; 1995a: 144) a partir de la presencia de protoarpones; numerosas azagayas alargadas de sección cilíndrica u ovalada; abundancia relativa de agujas y proliferación de varillas con secciones plano convexas y decoraciones geométricas dorsales; en ocasiones, con relieves tuberculados. Aunque en algunos yacimientos los proximales de azagaya más comunes son aplastamientos y biseles dobles, se ha observado una gama amplia de soluciones para enmangue, entre ellas las bases ahorquilladas. También se ha destacado la frecuencia de las reutilizaciones de azagayas, representadas por bases pedunculadas por recortes.

El registro de Oscura de Ania no cuenta con protoarpones ni azagayas de base ahorquillada, pero en líneas generales se ajusta al perfil esbozado: azagayas de sección circular con predominio del bisel doble y representación de otras soluciones de enmangue; presencia consistente de agujas y un número elevado de varillas con relieve tuberculado en su cara dorsal y estriación técnica ventral. También documenta una variabilidad amplia en las formas de trabajo, precisamente uno de los rasgos propuestos como característica del Magdaleniense medio (González Sáinz 1995: 167).

Un elemento interesante a la hora de establecer la filiación industrial del depósito magdaleniense de Oscura de Ania es la abundancia de varillas plano convexas con decoración dorsal en relieve tuberculado (Adán et al. e. p. a). Este tipo de varillas, abundantes en el registro de la Cueva (N.3: $3 ; \mathrm{N} \cdot 3 \mathrm{a}$ : 13 ; N.3b: 4), se ha documentado poco en yacimientos cantábricos: 1 ejemplar en las cuevas cántabras de La Chora (San Pantaleón de Aras, Voto) y del Valle (Gibaja, Rasines) y Urtiaga (Etxazpe, Itziar; Guipúzcoa). Esta última en el límite D inferior-D superior (González Sainz 1989a: 90-91, 97, 125, 
128, 241, figs. 29.27 y 50.6), si bien este ejemplo ofrece una morfología ligeramente distinta. En el nivel Magdaleniense inferior de la Cueva de Santimamiñe (Basondo, Vizcaya) apareció otra pieza (Utrilla 1981: 204, lámina 83) que, dada la semejanza con las anteriores, puede tratarse de una intrusión desde el Nivel VI (González Sainz 1989a: 107). Por último, en La Viña III se ha informado de la presencia de otras dos (Fortea et al. 1990: 225). Los ejemplos de La Chora, El Valle, Urtiaga y Santimamiñe, este último con mayor motivo, están mal definidos desde el punto de vista cronoestratigráfico: corresponden a niveles que representan intervalos de tiempo muy dilatados (González Sainz 1989a: 241). Lo mismo podría decirse de La Viña III, correspondiente al Magdaleniense superior o al medio, según zonas (Fortea 1996: 330).

A propósito de Oscura de Ania N.3a, se ha comentado que la presencia de varillas tuberculadas es relativamente común en el Magdaleniense medio, prolongándose hacia los inicios del superior (González Sáinz 1989a: 240-241). Manuel Pérez (1992: 641, nota 13) estableció paralelos con ejemplos de Gourgan y Mas d'Azil, correspondientes al Magdaleniense IV pirenaico. Por otra parte, su presencia en N.3b sugirió la adscripción de este Nivel al Magdaleniense medio pleno o superior inicial (Adán Álvarez 1997: 85). A juzgar por el contexto de Oscura de Ania, este tipo de varilla parece concentrarse en el Magdaleniense medio evolucionado sin ser extraño al Magdaleniense superior inicial o la transición Magdaleniense medio/superior.

En Oscura de Ania se han citado dos fragmentos de varillas plano convexas con decoración dorsal de surcos en relieve "tipo Isturitz", localizados en un revuelto del sector septentrional del vestíbulo de la Cueva (Pérez Pérez 1982). Este tipo de elementos se atribuye Magdaleniense medio en transición al Superior (González Sainz 1989a: 240), si bien en un primer momento se propuso que corresponderían a un horizonte magdaleniense anterior al documentado en el Nivel 3 de las publicaciones (Pérez Pérez 1982: 83-84). Su ausencia entre los materiales depositados en el MAA y el hecho de que el hallazgo se produjera fuera de contexto exige prudencia.

En primer lugar, no podemos asegurar que estos fragmentos realmente constituyan ejemplos de decoración "tipo Isturitz". Una alternativa es que se tratara de relieves tuberculados erosionados, tal como hemos podido apreciar en alguno de los fragmentos de varilla con tal motivo decorativo de este mismo yacimiento (Adán et al. e. p. a). En segun- do, desconocemos con detalle las circunstancias que rodearon su aparición y su correcta ubicación estratigráfica, que quizás podría solucionarse tras la revisión de los perfiles del yacimiento y el estudio de los diarios de excavación. No obstante, los yacimientos de la cuenca del Nalón con niveles del Magdalenienses medio típico, como Las Caldas y La Viña, cuentan con un arte mueble muy similar al del Magdaleniense IV pirenaico (Fortea 1989; 1990; 1992; Fortea et al. 1989; 1990) y este tipo de varillas no desentonaría dentro de este contexto. Tampoco puede soslayarse la posibilidad de que estas supuestas varillas "tipo Isturitz" pudieran ponerse en relación con ejemplares con decoraciones curvilíneas en distintas disposiciones documentados en depósitos del Magdaleniense medio y superior inicial como Hornos de la Peña (Tarriba, San Felices de Buelna; Cantabria); Cueto de la Mina C y Tito Bustillo 1c (González Sainz 1989a: 240).

El arte mueble magdaleniense de Oscura de Ania merece ser detallado en un futuro trabajo. Su análisis preliminar parece avalar la adscripción cronocutural del depósito (Adán et al. e. p. a). La pieza más interesante es un fragmento recortado y raspado de escápula, decorado con motivos figurativos y no figurativos, aparecido en N.3a (Figura 5). Su figura más espectacular, una cierva completa con las patas poco detalladas y realizada combinando grabado de contorno de trazo múltiple con estriado (13), fue atribuida a un momento inicial del Estilo IV Reciente de Leroi-Gourhan (Pérez Pérez 1992: 639-640). Esto es, a comienzos de la segunda fase del ciclo final magdaleniense de Jordá (1964).

El tema "cierva" es un motivo identificado en arte mueble cantábrico desde el Auriñaciense, alcanza su mayor protagonismo en el Magdaleniense inferior y el número de representaciones desciende en las fases avanzadas del Magdaleniense (Barandiarán 1989: 384). Por otra parte, parece que las figuras realistas no se asocian a signos de forma generalizada antes del Magdaleniense medio. En este mismo horizonte industrial comienza a utilizarse la combinación técnica en que se ejecutó la figura (Corchón 1986: 144, 154, 158) y tanto la realización de extremidades apenas esbozadas como la

(13) En el trabajo de presentación de la pieza se cita como rasgo estilístico "un ojo extrañamente redondo y pequeño, aunque correctamente situado, desentona respecto al naturalismo de otros rasgos (...)" (Pérez Pérez, 1992: 629-650). Tal ojo no forma parte de la figura, pues se trata del resultado de la acción de microorganismos sobre el hueso. Como otras marcas "puntiformes" que proliferan en la superficie de la pieza.

T. P., 59, n. $^{\circ} 2,2002$ 
representación de perfiles absolutos se proponen como rasgos característicos del arte mueble dè las fases avanzadas del Magdaleniense medio. A estas consideraciones iconográficas o estilísticas se suma el tipo de soporte: huesos con superficies propicias a constituir campos decorativos - como escápulas, pelvis, costillas y diáfisis gruesas- o astas poco o nada modificados parecen sustituir durante el Magdaleniense medio evolucionado a las elaboradas plaquetas que caracterizan el Magdaleniense medio típico (Corchón 1994: 253-255; 1995a, 146).

Exceptuando esta escápula y el arpón con supuesta figura de bóvido al que no hemos tenido acceso (vid supra), no hemos documentado representaciones figurativas entre los materiales magdalenienses de Oscura de Ania: el grueso del arte mueble lo constituye la industria ósea incisa. Dejando a un lado los ejemplares con relieves tuberculados, ya comentados, contamos con un número apreciable de azagayas y varillas con decoraciones lineales y curvilíneas. Precisamente, en el Magdaleniense medio evolucionado de La Paloma (6.65.2), Las Caldas (V-IV) y La Viña (IV superior) ha podido detectarse un sensible descenso de manifestaciones artísticas de corte figurativo, en contraste con la eclosión que caracteriza el tramo inmediatamente inferior (Corchón 1994: 253-256; 1995a: 152). En paralelo, aumenta la nómina de representaciones no figurativas sobre utillaje óseo, con un repertorio iconográfico que parece enlazar con las decoraciones desarrolladas durante el Magdaleniense superior inicial (que podría considerarse perfectamente como un Magdaleniense medio evolucionado muy avanzado, en transición hacia el superior) de, por ejemplo, Tito Bustillo 1c (ibidem).

En principio, los tubos óseos decorados y alguna azagaya con incisiones longitudinales documentados en nuestra revisión del registro y citados en bibliografía (Pérez Pérez 1977: 194-195, fig. 10.1$2,10.5-6)$ a priori supondrían una anomalía en contextos del Magdaleniense medio evolucionado. Los huesos de ave decorados con trazos simples formando series longitudinales parecen circunscribirse a momentos iniciales del Magdaleniense (Menéndez Fernández y García Sánchez 1998: 174). Cuando menos, eso parece señalar los ejemplares exhumados en las cuevas de Bolinkoba (Abadiano, Vizcaya); Altamira (Santillana del Mar, Torrelavega; Cantabria); El Castillo; Rascaño; La Paloma; Balmori (Barro, Llanes); La Güelga A (Narciandi, Cangas de Onís) y La Cuevona de Ribadesella (Corchón 1986: 256, 268, 274-275, 284, 308-309,
333-337, 471; Menéndez Fernández y García Sánchez 1998). No obstante, los motivos de ordenación axial, especialmente las series de incisiones en paralelo y las cruzadas en aspa o retículas de ejecución rápida se prodigan en el Magdaleniense medio y no resultan extraños en el Magdaleniense medio evolucionado (Corchón 1986: 101-102; 1994: 254).

En cuanto a Cueva Oscura N.3, la morfología de los arpones invita a situar el nivel en el Magdaleniense superior muy inicial, en la línea de los niveles de transición documentados en Las Caldas y, posiblemente, La Viña. En el primer yacimiento, el Nivel III de la Sala II ofrece una industria ósea que cuenta con prototipos del Magdaleniense medio evolucionado y del superior inicial, incluyendo un arpón típico. Incluso a techo del tramo V-IV, como en Ermittia II inferior/III superior, los protoarpones se asocian "a uno o dos fragmentos de arpones de una hilera de dientes bien conformados" (Corchón 1994: 256; 1995a: 144; 2000: 496). En cuanto a La Viña, el Estrato III proporcionó dos varillas con relieve tuberculado junto a azagayas a doble bisel y punzones decorados (Fortea et al. 1990: 225). Precisamente, Oscura de Ania N.3 cuenta con tres representantes de varillas con relieves tuberculados. No parece aventurado, pues, plantear que este tipo particular continuara apareciendo en los niveles superpuestos directamente al Magdaleniense medio en los yacimientos del occidente cantábrico.

Por otra parte, entre las piezas de industria ósea de Oscura de Ania citada en los primeros trabajos sobre la cueva que no hemos podido estudiar figura un supuesto arpón "con sección triangular y una sola hilera de dientes" (el fragmento representado cuenta con 7) y "acanaladuras longitudinales en el dorso del vástago y cortas incisiones sobre los dientes" (Gómez Tabanera et al. 1975: 65; Pérez Pérez 1977: 191, 195, fig. 10.4). A juzgar por la figura publicada, sus paralelos morfológicos podrían encontrarse en algunos arpones de La Pila 4.1 y El Pendo (González Sainz 1989a: 70, figs. 21.9 y 25.4) correspondientes a momentos avanzados del Magdaleniense superior. La publicación de estas descripciones precede en fecha al comienzo de la excavación de los materiales del Estrato III que conocemos, iniciada en la campaña de 1977 según el etiquetado de los mismos (14). La impresión que se desprende de estos artículos es que exponen los resultados de la primera campaña de trabajo de campo y que el depósito magdaleniense de Oscu-

(14) Cfr. lo expresado en la nota 4 en este mismo trabajo. 
ra de Ania era conocido por los excavadores bien gracias a un sondeo en área menor a la luego excavada, bien porque comenzara a excavarse con anterioridad a las fechas que figuran en el etiquetado de los materiales. Sea como fuere, la totalidad o una parte de los materiales que llevaron a definir el Estrato III (o su tramo superficial) como "Magdaleniense superior cantábrico" en los dos primeros artículos sobre la Cueva se encuentran ausentes de los fondos del MAA y no han podido incluirse en nuestra revisión.

\section{APROXIMACIÓN A LA CRONOESTRATIGRAFÍA DEL DEPÓSITO MAGDALENIENSE DE CUEVA OSCURA}

La parquedad de los comentarios disponibles sobre la sedimentología del depósito magdaleniense de Cueva Oscura de Ania (Pérez Pérez 1992: 641-642, nota 15) dificulta la tarea a la hora de ubicar correctamente el mismo desde un punto de vista cronoestratigrafico. Para N.3b conocemos una datación ${ }^{14} \mathrm{C}$ de $13500 \pm 150 \mathrm{BP}$ [GIF-5407] (15) (ibidem: 642), fecha que situaría esta capa arqueológica a finales del periodo paleoclimático Prebölling/ Cantábrico V o, quizás con mayor certeza, a comienzos de Bölling/Cantábrico VI (Adán Álvarez 1997: 85). Para N.3a contamos con otra de 11670 \pm 200 BP [GIF-5106] (16) (ibidem), correspondiente a un momento muy avanzado de Dryas II: prácticamente en transición hacia las primeras fases de Allërod/Cantrábico VIII. Esta última parece rejuvenecida, a juzgar por las características de su industria ósea. Si aceptamos como válidas las dos dataciones disponibles para el depósito magdaleniense de Oscura de Ania (17), su lapso cronológico es demasiado extenso. El Nivel 3b y, por extensión, el 3a fueron comparados a partir de la cronología absoluta del primero con Tito Bustillo 1c y el Magdaleniense medio de Las Caldas (ibidem: nota 17), extendiéndose hasta Alleröd. Sin embargo, la transición y el primer tramo de esta fase paleoclimática parecen estar representadas por el Nivel estéril superpuesto a N.3 y el Horizonte 0c, capa aziliense inferior del yacimiento. No en vano, la datación

\footnotetext{
(15) Calibrada a $1 \sigma 14432-13985$ BC; $2 \sigma 14643-13744$

(16) Calibrada a $1 \sigma 11910-11424$ BC; $2 \sigma 12184-11214$ $\mathrm{BC}$

(17) Tenemos noticias de que se enviaron para su análisis más muestras de toda la secuencia, aunque sus resultados nunca fueron publicados (Pérez Pérez, 1992: 642).
} BC. de $N \cdot 3$ a se solapa con la del Horizonte $0 \mathrm{~b}$, situada en $11880 \pm 200$ [GIF-5102] (18) (ibidem: nota 16), más acorde con las industrias analizadas para esta última capa arqueológica (Adán et al. 1999; 2001; e. p. b).

El Nivel arqueológicamente estéril que separa los depósitos magdalenienses y azilienses de Oscura de Ania fue descrito por los excavadores del yacimiento con un lacónico "capa de arcilla blanquecina" (Gómez Tabanera et al. 1975: 65; Pérez Pérez 1977: 191). Desconocemos, por tanto, su extensión y potencia. Sin embargo, su presencia parece concordar con capas estériles e hiatos sedimentarios que aíslan niveles magdalenienses en yacimientos cantábricos como los excavados en las cuevas cántabras de Morín (Villanueva de Villaescusa), El Pendo o El Rascaño (González Sainz 1989a: 159, cuadro IV.1). En esta última, tal discordancia ha sido asociada a una reactivación de la circulación interna de aguas kársticas que parece corresponder con Alleröd/Cantábrico VIII (Hoyos Gómez 1995: 64). En la cuenca media del Nalón, estos procesos parecen estar documentados en la erosión superficial de la Cueva de Las Caldas, que interesó a techo el Nivel I y prácticamente eliminó el tramo -I/-III de la Sala II (ibidem), cuyos retazos han sido definidos desde un punto de vista industrial como correspondientes al Magdaleniense superior final (Corchón 1991/92; 1999: 43). En La Paloma, se ha propuesto que esta oscilación está representada por el Nivel 3, prácticamente estéril y con numerosos restos de egagrópilas (González Sáinz 1989a: 155). En el oriente asturiano, el episodio bien pudiera corresponder a los procesos erosivos previos al Nivel 5, definido como Aziliense antiguo, de Los Azules I (Adán et al. 2001).

De acuerdo con estas consideraciones y atendiendo a la industria ósea por nosotros estudiada, el primer tramo magdaleniense de Oscura de Ania podría situarse entre finales de Dryas I superior/ Cantábrico V y Bölling/Cantábrico VI y el tramo superior, representado claramente en $\mathrm{N} \cdot 3$, a caballo entre Bölling/Cantábrico VI y Dryas II/Cantábrico VII. En este sentido, los escasos datos que conocemos sobre la sedimentología de los subniveles $3 a$ y $3 b$ (y posiblemente también para el 3) se ajustan, grosso modo, con el panorama esbozado para la progresión Cantábrico V-Cantábrico VIinicios de Cantábrico VII dentro de la paleoclima-

(18) Calibrada a $1 \sigma 12169-11649$ BC; $2 \sigma 12464-11422$ $\mathrm{BC}$

T. P., 59, n. ${ }^{\circ} 2,2002$ 
tología del Tardiglaciar cantábrico establecida a partir del análisis sedimentológico. Los datos disponibles para yacimientos de la cuenca media del Nalón con representación de este episodio, como La Paloma, Las Caldas, La Viña o Entrefoces, coinciden en señalar un descenso paulatino de cantos de gelivación y el incremento de la fracción fina arcilloarenosa para, a continuación, mostrar nuevamente indicios de clima frío (Hoyos Gómez 1995).

\section{REFLEXIONES FINALES}

El primer horizonte magdaleniense identificado en Cueva Oscura de Ania parece corresponder con los rasgos que caracterizan el Magdaleniense medio evolucionado. Cuando menos, esta posibilidad señala tanto el análisis de la industria ósea como la datación disponible para $\mathrm{N} \cdot 3 \mathrm{~b}$, coherente con las conocidas para otros depósitos adscritos a este horizonte industrial (Corchón 1995b). Bien documentado en Las Caldas VI-V, el Magdaleniense medio evolucionado parece constituir parte de la adaptación de los grupos humanos de la Cornisa Cantábrica a las condiciones climáticas que caracterizan el episodio conocido como Bölling/Cantábrico VI (Corchón 1995a: 150). Otros depósitos del área cantábrica que a buen seguro reflejan este mismo fenómeno son La Viña IV superior, La Paloma 6.65.2, Tito Bustillo 2, Cueto de La Mina C y Abauntz e (Arraiz, Navarra). Es muy posible que el catálogo se complete con depósitos de adscripción estratigráfica imprecisa o aún poco conocidos como parte de El Pendo II y Santimamiñe VII, Ermittia II inferior/III superior, Lumentxa D o Cierro III (Corchón 1994: 253, 1995a: 142-148; 2000: 496).

La ubicación cronoestratigráfica precisa del segundo horizonte magdaleniense de Oscura de Ania plantea mayores problemas. En primer lugar, no contamos con dataciones radiocarbónicas que contribuyan a aclarar su situación. El análisis tecnomorfológico de la industria ósea señala que se trata de una fase avanzada del Magdaleniense medio evolucionado, en transición hacia el Magdaleniense superior, como la documentada en Las Caldas III o La Viña III y, muy posiblemente, techo de IV superior. Sin embargo, tampoco puede desecharse la posibilidad de que represente, cuando menos parcialmente, el Magdaleniense superior inicial: el tránsito Magdaleniense medio/superior constituye un proceso suave, sin rupturas, a juzgar por los datos disponibles de Las Caldas III-II o Tito Bustillo 1c-2 (Corchón 2000: 496-497). En este sentido, la fecha ${ }^{14} \mathrm{C}$ proporcionada por Las Caldas III -13 185 £ 155 BP [Ua-10191] (Corchón 1999: 44)es poco más tardía que la de Oscura de Ania $3 b$. De este modo, puede plantearse la posibilidad de que el tramo magdaleniense superior identificado en este último yacimiento pueda corresponder con los momentos iniciales de Dryas II/Cantábrico VII.

El horizonte industrial denominado Magdaleniense medio evolucionado o tardío de la Cornisa Cantábrica se ha definido en los últimos años gracias al registro de Las Caldas y La Viña, dos ricos yacimientos del Nalón. Aunque los niveles cantábricos que parecen corresponder a este tecnocomplejo comparten algunos rasgos comunes en cuanto a los repertorios de industria ósea, la tónica dominante es cierta heterogeneidad. Ésta circunstancia no permite establecer un cuadro diacrónico y sincrónico claro (Esparza y Mújika 1999: 65). En cualquier caso, la diversidad de las asociaciones tipológicas y de las soluciones técnicas -manifestada de forma evidente en la coexistencia de diferentes soluciones de enmangue en azagayas y la convivencia en algunos casos de arpones toscos con protoarpones y azagayas ahorquilladas-bien pudiera interpretarse como indicio de una transformación acelerada y continua en las comunidades que habitaron la región durante este segmento cronológico. De ahí la dificultad de adscripción que aparentemente plantean niveles como Tito Bustillo 1c. A pesar de su datación ${ }^{14} \mathrm{C}$, su registro invita a pensar que corresponde a la continuación inmediata del Magdaleniense medio evolucionado (Fortea 1989: 429). De la misma forma, el depósito magdaleniense de Oscura de Ania parece ser fiel representación de este panorama. Se hace necesario, no obstante, solucionar los problemas estratigráficos que plantea el yacimiento y el estudio pormenorizado de su fauna a la hora de interpretar el significado y el alcance real de los procesos de cambio suave y continuado que pueden apreciarse a partir del estudio de su industria ósea.

Ya comentamos en aparatados anteriores la ausencia de los fondos del MAA de materiales arqueológicos exhumados en Oscura de Ania. Alguno de estas piezas, publicadas de forma imprecisa por los excavadores del yacimiento, invita a pensar que en el mismo estuvo representado un estadio Magdaleniense más avanzado. Esta circunstancia abre dos posibilidades. La primera, que el Nivel 3 de la bibliografía clásica (nuestro Estrato III) constituyera o comprendiera una capa superior a las que conoce- 
mos, correspondiente a un Nivel Magdaleniense superior pleno y cuyo registro nunca fue entregado. La segunda, que el yacimiento contara (o cuente) con retazos de niveles correspondientes a momentos más tardíos de Dryas II/Cantábrico VII erosionados por los procesos sedimentarios correspondientes a la transición Alleröd/Cantábrico VIII, tal como se documenta en el tramo -I/-III de Las Caldas.

Ante lo expuesto anteriormente, se hace necesario señalar que estas reflexiones en torno al depósito arqueológico de Cueva Oscura de Ania constituyen conclusiones preliminares y planteamientos de trabajo que precisan una contrastación sobre el terreno. A buen seguro, el avance de nuestro estudio del registro del yacimiento; la revisión de los diarios de campo -a los cuales no hemos tenido acceso- y de su estratigrafía; la realización de análisis sedimentológicos y polínicos y la toma de nuevas muestras para dataciones contribuirá a aclarar aún más la cronoestratigrafía del yacimiento. Particularmente la de sus niveles magdalenienses, aquellos que actualmente plantean más incertidumbres y problemas de adscripción.

\section{BIBLIOGRAFÍA}

ADÁN ÁLVAREZ, G. E. 1997: De la Caza al útil. La industria Ósea del Tardiglaciar en Asturias. Servicio de Publicaciones del Principado de Asturias, Oviedo.

ADÁN ÁlVAREZ, G. E.; GARCÍA SÁNCHEZ, E. y QUESADA LÓPEZ, J. M. 1999: "El Aziliense de Cueva Oscura de Ania (Las Regueras, Asturias): Primera aproximación y su contexto en la cuenca del Nalón". Espacio, Tiempo y Forma. Serie I 12: 215-267.

- 2001: "Cueva Oscura de Ania (Las regueras, Asturias): Contribución al conocimiento del aziliense antiguo cantábrico". Complutum 12: 9-32.

- e. p. a: "Cueva Oscura de Ania (Las Regueras, Asturias, España) y la definición del Aziliense antiguo: La industria ósea". En Actas del XXVI Congreso Nacional de Arqueología. Zaragoza, 18-21 de abril de 2001. Fundación Fernando el Católico, Zaragoza.

- e. p. b: "Avance al estudio del Magdaleniense de Cueva Oscura de Ania (Las Regueras, Asturias, España)". En Actas del XXVI Congreso Nacional de Arqueología. Zaragoza, 18-21 de abril de 2001. Fundación Fernando el Católico, Zaragoza.

BARANDIARÁN MAESTU, I. 1989: "El Magdaleniense en Asturias, Cantabria y País Vasco: Constantes y variabilidad del arte portátil". En J.-P. Rigaud (ed.): Le Magdalénien en Europe. La structuration du Magdalenien. Actes du Colloque de Mayence, 1987. 379-396. ERAUL, 38. Universidad de Lieja, Lieja.
CHAPA BRUNET, T. y MARTÍNEZ NAVARRETE, M ${ }^{\mathrm{a}}$ I. 1977: "Pieza inédita del arte mueble asturiano". En Actas del XIV Congreso Nacional de Arqueología (Vitoria, 1975). 165-174. Zaragoza.

CORCHÓN RODRÍGUEZ, $\mathrm{M}^{\mathrm{a}}$ S. 1986: El arte mueble paleolítico cantábrico. Contexto y análisis interno. Centro de Investigación y Museo de Altamira/Monografías, 16. Ministerio de Cultura, Madrid.

-_ 1991/92: "Representaciones de fauna fría en el arte mueble de la Cueva de Las Caldas (Asturias, España). Significación e implicaciones en el arte parietal”. Zephyrus XLIV-XLV: 35-64.

- 1994: "Últimos hallazgos y nuevas interpretaciones del arte mueble paleolítico en el occidente asturiano". En $M^{a}$. T. Chapa Brunet y M. Menéndez Fernández (eds): Arte Paleolítico. Complutum 5: 235-264.

-_ 1995a: "El Magdaleniense Medio Cantábrico: Nuevas evidencias". En A. Moure Romanillo y C. González Sainz (eds.): El Final del Paleolítico Cantábrico: Transformaciones ambientales y culturales durante el Tardiglacial y comienzos del Holoceno en la Región Cantábrica. Universidad de Cantabria, Santander: 119158.

- 1995b: "Reflexiones acerca de la cronología del Magdaleniense cantábrico. Las dataciones $14 \mathrm{C}$ de la Cueva de Las Caldas (Asturias, España)". Zephyrus XLVIII: 3-19.

-_ 1999: "La cueva de Las Caldas (Priorio, Oviedo). IV. Excavaciones 1995-1998”. En Excavaciones arqueológicas en Asturias 1995-1998. Consejería de Educación y Cultura del Principado de Asturias, Oviedo: 4357.

- 2000: "Novedades en el arte mueble magdaleniense del occidente de Asturias (España)". En Paleolítico da Península Ibérica. Actas do $3^{\circ}$ Congresso de Arqueologia Peninsular, II. 493-523. Oporto.

ESPARZA SAN JUAN, X. y MÚJIKA ALUSTIZA, A. 1999: "Reflexiones en torno a la estratigrafía de Ermittia (Deva, Guipúzcoa)". En Actas del XXIV Congreso Nacional de Arqueología: Volumen I: El Paleolítico superior mediterráneo y sus problemas (Cartagena, 1997). 61-69. Cartagena.

FORTEA PÉREZ, J 1989: "El Magdaleniense medio en Asturias, Cantabria y el País Vasco". En J.-P. Rigaud (ed.): Le Magdalénien en Europe. La structuration du Magdalénien. Actes du Colloque de Mayence 1987. 419-437. ERAUL, 38. Universidad de Lieja, Lieja.

- 1990: "Abrigo de La Viña. Informe de las campañas 1980 a 1986". En Excavaciones arqueológicas en Asturias 1980-1986. Consejería de Educación y Cultura del Principado de Asturias, Oviedo: 55-68.

- 1992: "Abrigo de La Viña. Informe de las campañas 1987 a 1990". En Excavaciones arqueológicas en Asturias 1987-1990. Consejería de Educación y Cultura del Principado de Asturias, Oviedo: 19-28.

- 1996: "Le Paléolithique supérieur en Espagne: Galice

T. P., 59, n. ${ }^{\circ} 2,2002$ 
et Asturies (1991-1995)”. En M. Otte (ed.): Le Paléolithique supérieur en europeen. Bilan Quinquenal. ERAUL, 76. UISSPP, Forli: 330-343.

FORTEA PÉREZ, J.; CORCHÓN RODRÍGUEZ, Ma S.; GONZÁLEZ MORALES, M.; RODRÍGUEZ ASENSIO, A.; HOYOS GÓMEZ, M.; LAVILLE, H.; DUPRÉ, M. y FERNÁNDEZ-TRESGUERRES, J. 1989:

- "Neue Untersuchungen in den Fluâtälern des Nalón und des Sella (Asturien)". Madrider Mitteilungen 30: $1-30$.

- 1990: "Travaux Récents dans les Vallées du Nalón et du Sella (Asturies)". En J. CLOTTES (ed.): L'art des objets au Paléolithique. T. I: L'art mobilier et son contexte. Colloque International Foix-Mas d'Azil. 16-21 novembre 1987. 219-244. Ministère de la Culture, de la Communication, des Grand Travaux et du Bicentenaire, Clemency.

GÓMEZTABANERA, J. M. 1975: "Catalogue des grottes et gisements préhistoriques dans l'est des Asturies". Bulletin de la Société Préhistorique de l'Ariège XXX: 29-57.

- 1980: La caza en la Prehistoria (Asturias, Cantabria Euskal-Herría). Ediciones Istmo, Madrid.

GÓMEZ TABANERA, J. M.; PÉREZ PÉREZ, M.; CANO DÍAZ, J. 1975: "Première prospection de "Cueva Oscura de Ania" dans le bassin du Nalon (Las Regueras, Oviedo) et conaissance de ses vestiges d'Art Rupestre". Bulletin de la Société Préhistorique de l'Ariège XXX: 59-69.

GONZÁLEZ SÁINZ, C. 1989a: El Magdaleniense superior-final de la región cantábrica; Tantin. Santander.

- 1989b: "El Magdaleniense superior-final de la región cantábrica". En J.-P. Rigaud (ed.): Le Magdalénien en Europe. La structuration du Magdalénien. Actes du Colloque de Mayence, 1987. 441-455. ERAUL, 38. Universidad de Lieja, Lieja.

- 1995: "13.000-11.000 B. P.: El final de la época magdaleniense en la Región Cantábrica”. En A. Moure Romanillo y C. González Sainz (eds.): El final del Paleolítico cantábrico. Transformaciones ambientales y culturales durante el Tardiglacial y comienzos del Holoceno en la Región Cantábrica. Universidad de Cantabria, Santander: 199-224.

HOYOS GÓMEZ, M. 1995: "Paleoclimatología del Tardiglacial en la Cornisa Cantábrica basada en los resultados sedimentológicos de yacimientos arqueológicos de yacimientos kársticos”. En A. Moure Romanillo y C. González Sainz (eds.): El final del Paleolítico cantábrico. Transformaciones ambientales y culturales durante el Tardiglacial y comienzos del Holoceno en la Región Cantábrica. Universidad de Cantabria, Santander: 1575.

JORDÁ CERDÁ, F. 1964: "Sobre técnicas, temas y etapas del Arte Paleolítico de la región cantábrica". Zephyrus XV: 5-25

MARTÍNEZ NAVARRETE, $M^{\mathrm{a}}$ I. y CHAPA BRUNET, T. 1980: "La industria prehistórica de la Cueva de La Paloma (Soto de las Regueras, Asturias)". En M. Hoyos Gómez, M. I. Martínez Navarrete, T. Chapa Brunet, P. Castaños y F. B. Sanchíz (eds.): La Cueva de La Paloma. Soto de Las Regueras (Asturias). Excavaciones Arqueológicas en España 116; Ministerio de Cultura, Madrid: 115-204.

MENÉNDEZ FERNÁNDEZ, M. 1997: "Historiografía y novedades del arte mueble paleolítico en la Península Ibérica". Espacio, Tiempo y Forma. Serie I 10: 129173.

MENÉNDEZ FERNÁNDEZ, M. y GARCÍA SÁNCHEZ, E. 1998: "Instrumentos musicales paleolíticos: La flauta magdaleniense de la Cueva de La Güelga (Asturias)". Espacio, Tiempo y Forma. Serie I 11: 167-177.

MOURE ROMANILLO, J. A. 1985: "Nouveautés dans l'art mobilier figurative du Paléolithique cantabrique". Bulletin de la Société Préhistorique de l'Ariège XXXX: 99-129.

PÉREZ PÉREZ, M. 1977: "Presentación de algunos materiales procedentes de Cueva Oscura de Ania, Las Regueras (Asturias)". En Actas del XIV Congreso Nacional de Arqueología (Vitoria, 1975). 179-196. Zaragoza.

- 1982: "Las varillas semicilíndricas decoradas de Cueva Oscura de Ania, Las Regueras (Oviedo)". Sautuola III: $79-85$.

- 1992: "Un hueso grabado de "Cueva Oscura de Ania" (Las Regueras, Asturias)". Boletín del Real Instituto de Estudios Asturianos 140: 625-650.

POLITIS, G. G. 1998: “Arqueología de la Infancia: Una perspectiva etnoarqueológica". Trabajos de Prehistoria 55 (2): 5-19.

UTRILLA MIRANDA, P. 1981: El Magdaleniense inferior y medio en la costa cantábrica. Centro de Investigación y Museo de Altamira: Monografías, 4. Ministerio de Cultura, Madrid. 